\title{
Determining dominant scatterers of sound in mixed zooplankton populations
}

\author{
Andone C. Lavery ${ }^{a)}$ \\ Department of Applied Ocean Physics and Engineering, Woods Hole Oceanographic Institution, \\ Woods Hole, Massachusetts 02543 \\ Peter H. Wiebe \\ Biology Department, Woods Hole Oceanographic Institution, Woods Hole, Massachusetts 02543 \\ Timothy K. Stanton \\ Department of Applied Ocean Physics and Engineering, Woods Hole Oceanographic Institution, \\ Woods Hole, Massachusetts 02543 \\ Gareth L. Lawson \\ Hopkins Marine Station of Stanford University, Pacific Grove, California 93950 \\ Mark C. Benfield \\ Department of Oceanography and Coastal Sciences, Louisiana State University, Baton Rouge, \\ Louisiana 70803 \\ Nancy Copley \\ Biology Department, Woods Hole Oceanographic Institution, Woods Hole, Massachusetts 02543
}

(Received 6 April 2006; revised 28 August 2007; accepted 7 September 2007)

\begin{abstract}
High-frequency acoustic scattering techniques have been used to investigate dominant scatterers in mixed zooplankton populations. Volume backscattering was measured in the Gulf of Maine at 43, 120, 200, and $420 \mathrm{kHz}$. Zooplankton composition and size were determined using net and video sampling techniques, and water properties were determined using conductivity, temperature, and depth sensors. Dominant scatterers have been identified using recently developed scattering models for zooplankton and microstructure. Microstructure generally did not contribute to the scattering. At certain locations, gas-bearing zooplankton, that account for a small fraction of the total abundance and biomass, dominated the scattering at all frequencies. At these locations, acoustically inferred size agreed well with size determined from the net samples. Significant differences between the acoustic, net, and video estimates of abundance for these zooplankton are most likely due to limitations of the net and video techniques. No other type of biological scatterer ever dominated the scattering at all frequencies. Copepods, fluid-like zooplankton that account for most of the abundance and biomass, dominated at select locations only at the highest frequencies. At these locations, acoustically inferred abundance agreed well with net and video estimates. A general approach for the difficult problem of interpreting high-frequency acoustic scattering in mixed zooplankton populations is described. (C) 2007 Acoustical Society of America.
\end{abstract}

[DOI: 10.1121/1.2793613]

PACS number(s): 43.30.Pc, 43.30.Sf, 43.30.Ft [KGF]

Pages: $3304-3326$

\section{INTRODUCTION}

High-frequency acoustic scattering techniques provide a unique remote sensing capability to rapidly and synoptically investigate zooplankton distributions on similar spatial and temporal scales to the physical processes influencing them. Zooplankton are key components of pelagic food webs and yet determining their temporal and spatial distributions and abundances is an ongoing challenge. Zooplankton distributions are inherently complex, patchy at many scales, and influenced by physical processes at many different scales, from small turbulence scales $(\mathrm{mm}$ to $\mathrm{cm}$ ) (Rothschild and

\footnotetext{
a) Author to whom correspondence should be addressed. Electronic mail: alavery@whoi.edu
}

Osborn, 1988; Seuront et al., 2001) to basin scales (tens to hundreds of km) (Haury et al., 1978). Adding further complexity, zooplankton aggregations are often highly heterogeneous and some zooplankton are active swimmers, resulting in distributions that are not simply a passive response to the physical processes influencing them, such as turbulence or advection, but an intricate coupling of behavior and physical forcing.

Over the last two decades, the use of high-frequency acoustic scattering techniques has become more routine for synoptic studies of zooplankton populations from centimeter to kilometer scales and across seasonal time scales (Wiebe et al., 1996, 1997; Brierley et al., 1998; Pieper et al., 2001; Lawson et al., 2004), a task not as easily achievable by traditional net or optical sampling techniques alone. Although 
traditional single-frequency echosounders are frequently used for visualizing zooplankton populations, there remain inherent difficulties associated with the interpretation of the acoustic scattering returns even when direct and coincident measurements of the scattering sources are available. Difficulties associated with the interpretation of the acoustic returns are reduced in regions in which a single zooplankton taxon dominates the scattering, e.g., Euphausia superba in Antarctic regions (Lascara et al., 1999), or the relative abundance of zooplankton taxa remains constant (Benfield et al., 1998). Holliday and Pieper (1995) review the circumstances when single-frequency acoustic scattering returns can be successfully interpreted. Multi-frequency acoustic scattering techniques expand the range of conditions under which it is possible to interpret the acoustic data in terms of relevant biological parameters, such as animal size or abundance (Holliday and Pieper, 1980, 1995; Costello et al., 1989; Pieper et al., 1990; Napp et al., 1993; Wiebe et al., 1997; Korneliussen and Ona, 2002; Warren et al., 2003; Mair et al., 2005; Trevorrow et al., 2005; Lawson et al., 2006).

A major complicating factor in the use of highfrequency sound to characterize zooplankton is the diverse array of organisms present in the water column (Fig. 1). Zooplankton aggregations typically span a wide range of sizes, shapes, orientations, and material properties: all parameters that influence the scattering of sound and that can be difficult to quantify. In order to understand the scattering from the wide diversity of zooplankton, it is convenient to categorize zooplankton into three groups based on the boundary conditions and anatomy (Stanton et al., 1994, 1998a, b): 1) weakly scattering fluid-like zooplankton, for which the density and sound speed contrasts are small relative to the surrounding water, 2) zooplankton with hard elastic shells, which scatter sound efficiently relative to fluid-like zooplankton of similar size, and 3) zooplankton with gas inclusions that can give rise to strong scattering resonances. The vast majority of zooplankton biomass and numerical abundance is made up of fluid-like zooplankton, typically copepods. However, there are many locations where fluidlike zooplankton collectively only make up a small fraction of the scattered energy, which is instead dominated by less abundant, but more efficient scatterers of sound, such as pteropods (hard elastic shell category) and siphonophores (gas-bearing category). There are also other potentially confounding factors, such as the presence of fish, squid, bubbles, and suspended sediments that may contribute to the scattering. Further compounding difficulties in the interpretation is the fact that microstructure has been shown to contribute significantly to scattering, although only under some, possibly limited, conditions (Warren et al., 2003), and can be co-located with the zooplankton. As a result of the often simultaneous presence of many different types of scatterers in mixed zooplankton populations, the estimation of biologically meaningful quantities, such as animal abundance or size, from measurements of high-frequency volume backscattering, called the "inverse problem," is generally highly under-determined.

In order to address some of the challenges associated with the interpretation of high-frequency acoustic scattering
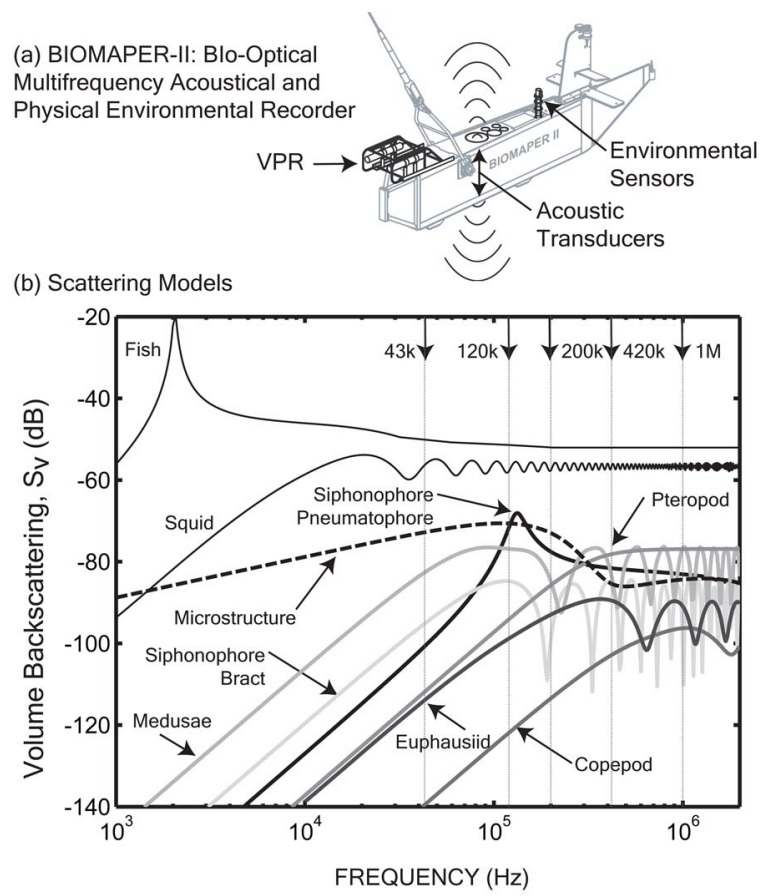

FIG. 1. (Color online) (a) BIOMAPER-II. (b) Volume backscattering as a function of frequency for the major biological scatterers observed in the GoM, assuming a numerical abundance of 1 organism $/ \mathrm{m}^{3}$. The five BIOMAPER-II frequencies are indicated by vertical lines. The predictions are based on mean lengths in the 75-100 m depth range of MOCNESS 4 in Jordan Basin, GoM, in December 1999: pneumatophore $=0.27 \mathrm{~mm}$, siphonophore bract $=9.86 \mathrm{~mm}$, copepod $=1.53 \mathrm{~mm}$, euphausiid $=9.79 \mathrm{~mm}$, and pteropod $=1.15 \mathrm{~mm}$. The medusa length $(16.53 \mathrm{~mm})$ is based on the deepest net as none were observed at mid depths. A DWBA-based prolate spheroid scattering model was used for squid (length $=9 \mathrm{~cm}$, width $=1.2 \mathrm{~cm}$, density contrast $g=1.043$, sound speed contrast $h=1.053$ ) (Iida et al., 2006), averaged over a normal distribution of angles of orientation with a mean of $0^{\circ}$ (corresponding to broadside incidence) and a standard deviation of $30^{\circ}$. The hybrid model with a 1-cm-diam gas bubble was used to represent the scattering from swim-bladdered fish. Also included are microstructure predictions using a dissipation rate of turbulent kinetic energy $\varepsilon$ $=1 \times 10^{-6} \mathrm{~m}^{2} / \mathrm{s}^{3}$ and the maximum temperature and salinity gradients observed for CTD 2 in Jordan Basin, GoM, in December 1999, representing an upper-bound estimate for the contribution to scattering from turbulent microstructure.

from mixed zooplankton populations, a towed instrument platform, BIOMAPER-II (BIo-Optical Multi-frequency Acoustical and Physical Environmental Recorder), was developed (Wiebe et al., 2002) that allows coincident measurement of multi-frequency acoustic backscattering, temperature, salinity, depth, and high-resolution zooplankton video images (Fig. 1). BIOMAPER-II has been used to perform broad-scale surveys of mixed zooplankton populations in the deep basins of the Gulf of Maine (GoM) and results from these surveys are presented in this study. Supplementing the data collected with this instrument are almost-coincident net samples and conductivity, temperature, and depth (CTD) profiles.

The almost-simultaneous use of net and video sampling techniques (often referred to as "ground truthing") with the collection of acoustic data helps constrain the otherwise highly under-determined inverse problem and increases the range of circumstances under which dominant scatterers can be identified. Comparison of observed to predicted volume scattering (based on scattering models that incorporate net 
and/or video measurements of animal size, shape, and abundance), known as the "forward problem," allows dominant water-column scatterers to be determined. Once these have been determined, volume backscattering measurements can then be used to invert for biologically relevant parameters, such as size or abundance, at least at some restricted locations.

In this study, the volume sampled acoustically with BIOMAPER-II is sufficiently large that a two-dimensional cross section, or "curtain," of the ocean interior is imaged, and a significant fraction of the zooplankton taxa present in the water column is included in the sampling volume, typically involving multiple trophic levels. This is in contrast to zooplankton video imaging instruments, such as the Video Plankton Recorder (Davis et al., 1992), and some acoustic instruments (Holliday and Pieper, 1995; Pieper et al., 1990, 2001; Costello et al., 1989, Napp et al., 1993), which sample smaller volumes (up to four orders of magnitude smaller), require profiling, and result in one-dimensional measurements of the water column. In addition, instruments with small sampling volumes typically do not adequately sample less abundant and/or larger taxa, such as gas-bearing siphonophores, and are instead optimized for sampling small and abundant scatterers, such as copepods. Yet, typical zooplankton surveys use hull-mounted or towed acoustic platforms (such as BIOMAPER-II) with relatively large acoustic sampling volumes, and thus sample the less abundant and/or larger taxa that often dominate the scattering, at least over a range of frequencies. In addition, the less abundant and/or larger taxa are important to sample in order to understand the entire pelagic food web. However, the contribution to scattering from multiple different taxa can also lead to additional complexities in interpreting the returns. Finally, though less abundant and/or larger taxa are sampled by many net systems, net techniques often have coarse depth resolution, destroy fragile individuals, suffer from selective sampling due to avoidance or escapement, and require time-consuming analysis. As a result of the inherent limitations of any one technique, the combined use of multi-frequency acoustic, video, and net sampling techniques increases the likelihood of correctly identifying dominant scatterers and determining biologically meaningful parameters.

The specific objectives of this work are to: 1) Assess the limitations of existing scattering models and their input parameters, and the implications of these limitations to the determination of dominant scatterers in mixed zooplankton populations. To reduce discrepancies between predicted and observed volume backscattering, minor modifications are made to existing scattering models for gas-bearing and elastic-shelled zooplankton. 2) Use direct video and net sampling techniques together with the scattering models to make forward predictions of expected backscattering in order to determine dominant water-column scatterers, and deduce the distribution and variability of the dominant water-column scatterers. 3) Compare predicted volume backscattering with measured volume backscattering at multiple frequencies, locations, and depths. 4) Perform simple inversions for biologically relevant parameters in regions where the scattering is shown by the forward predictions to be dominated by a single zooplankton taxon. 5) Make recommendations for conditions under which these methods for quantitative studies of mixed zooplankton populations can be used.

\section{SCATTERING MODELS AND PARAMETERS}

There are many potential water-column scattering sources, including zooplankton and micronekton (e.g., shrimp, fish, and squid), phytoplankton, suspended sediments, bubbles, and microstructure. Throughout this work, shrimp and zooplankton are referred to collectively as "zooplankton." Accurate scattering models for different scattering sources (Fig. 1), together with information obtained from net and video sampling techniques, are key to determining dominant water-column scatterers. In this section, the models used to compare measured to predicted volume backscattering from zooplankton and microstructure are described. Sensitivity analyses of some of the necessary parameters are discussed elsewhere in the literature (e.g. Stanton and Chu, 2000; Lavery et al., 2001).

\section{A. Basic equations}

For a single bounded target, the backscattering amplitude, $f_{\mathrm{bs}}$, is a measure of the efficiency with which the target scatters sound in the backscattering direction, and is a function of the acoustic frequency, orientation of the target relative to the incident wave, the size and shape of the target, and the density $\left(g=\rho_{\text {target }} / \rho\right.$, where $\rho_{\text {target }}$ is the density of the target and $\rho$ is the water density) and sound speed ( $h$ $=c_{\text {target }} / c$, where $c_{\text {target }}$ is the sound speed of the target and $c$ is the water sound speed) contrasts between the target and surrounding water. The far-field backscattered energy is often expressed in terms of the target strength (TS) with units of decibel $(\mathrm{dB})$ relative to $1 \mathrm{~m}^{2}$ and is given by TS $=10 \log _{10} \sigma_{\mathrm{bs}}=10 \log _{10}\left|f_{\mathrm{bs}}\right|^{2}$, where $\sigma_{\mathrm{bs}}=\left|f_{\mathrm{bs}}\right|^{2}$ is the differential backscattering cross section and differs from the oftenused scattering cross section $\sigma$ by a factor of $4 \pi(\sigma$ $\left.=4 \pi \sigma_{\mathrm{bs}}\right)$. For spherical targets of radius $a$, the reduced target strength (RTS) is given by $\mathrm{RTS}=10 \log _{10}\left(\sigma_{b s} / \pi a^{2}\right)$. Mean $\mathrm{TS}$ and RTS are defined as $\langle\mathrm{TS}\rangle=10 \log _{10}\left\langle\sigma_{\mathrm{bs}}\right\rangle$ and $\langle\mathrm{RTS}\rangle$ $=10 \log _{10}\left\langle\sigma_{\mathrm{bs}} / \pi a^{2}\right\rangle$.

During most field experiments, it is not the scattering from a single individual that is measured, but instead the average over many individual targets. So long as the phases from the echoes of the individual targets are random, and there is no attenuation or multiple scattering, then the average echo energy from the aggregation is equal to the sum of the echo energy from each individual, averaged over an ensemble of independent realizations, for example, averaged over animal orientation, length, or a combination of the two. The echo integration procedure results in an estimate of the volume backscattering coefficient, $s_{V}$, with units of $\mathrm{m}^{2} / \mathrm{m}^{3}$, which corresponds to the scattered echo energy at the receiver from the aggregation of scatterers normalized by the scattering volume. For an aggregation of zooplankton 


$$
s_{V}\left(f_{q}, d_{k}\right)=\frac{1}{V_{k}} \sum_{i=1}^{N_{k}} \sum_{j=1}^{M_{k}}\left\langle\sigma_{\mathrm{bs}}^{i j}\left(f_{q}, d_{k}, \Psi_{i j}\right)\right\rangle
$$

where $f_{q}$ is the frequency, $V_{k}$ is the volume of water sampled in the depth range $d_{k}, N_{k}$ is the number of zooplankton of a particular taxon in the depth range $d_{k}, M_{k}$ is the number of zooplankton taxa in the depth range $d_{k}$, and $\left\langle\sigma_{\mathrm{bs}}^{i j}\left(f_{q}, d_{k}, \Psi_{i j}\right)\right\rangle$ is the backscattering cross section of each individual of size $i$, taxon $j$, at frequency $f_{q}$, in the depth range $d_{k}$. The term $\langle\ldots\rangle$ represents an average over angles of orientation. The parameter $\Psi_{i j}$ includes the dependence of $\sigma_{\mathrm{bs}}$ on a number of taxon-specific parameters not explicitly written into the equation, such as shape and material properties. All parameters are assumed to be constant for all individuals of a given taxon, other than size. The volume backscattering strength is given by $S_{V}=10 \log _{10} s_{V}$, which has units of decibel (dB) relative to an inverse meter. Multiple sources of scattering in the same sampling volume are accounted for by incoherently adding their contributions (e.g., $S_{V}^{\text {total }}=10 \log _{10}\left(s_{V}^{\text {zooplankton }}\right.$ $\left.+s_{V}^{\text {microstructure }}\right)$ ).

\section{B. Turbulent microstructure}

Under certain circumstances it is possible for turbulent oceanic microstructure to result in acoustic backscattering levels comparable to those observed for zooplankton (Thorpe and Brubacker, 1983; Seim et al., 1995; Seim, 1999; Goodman, 1990; Lavery et al., 2003; Ross and Lueck, 2003; Warren et al., 2003). Failure to account for the contribution to scattering from microstructure can lead to overestimates of zooplankton numerical abundance, as well as difficulties in interpreting frequency-dependent scattering spectra. The volume backscattering coefficient for turbulent microstructure is given by (Lavery et al., 2003; Ross et al., 2004)

$$
\begin{aligned}
s_{V}= & \left(\frac{k^{4}}{K^{3}}\right) q\left(\frac{\nu}{\varepsilon}\right)^{\frac{1}{2}}\left\{A^{2} \chi_{T} \exp \left(-q \frac{K^{2}}{k_{\mathrm{BT}}^{2}}\right)+B^{2} \chi_{S}\right. \\
& \left.\exp \left(-q \frac{K^{2}}{k_{\mathrm{BS}}^{2}}\right)+A B\left(\chi_{T} \chi_{S}\right)^{\frac{1}{2}} \exp \left(-q \frac{K^{2}}{k_{\mathrm{BTS}}^{2}}\right)\right\},
\end{aligned}
$$

where $k$ is the acoustic wave number, $K=2 k$ is the Bragg wave number in the backscattering direction, $A$ $=c^{-1}(\partial c / \partial T)+\rho^{-1}(\partial \rho / \partial T)$, and $B=c^{-1}(\partial c / \partial S)+\rho^{-1}(\partial \rho / \partial S)$. The term $\varepsilon$ is the dissipation rate of turbulent kinetic energy $\left[\mathrm{m}^{2} / \mathrm{s}^{3}\right], \nu\left[\mathrm{m}^{2} / \mathrm{s}\right]$ is the molecular viscosity, and $q$ is a universal constant $\left(q=3.7\right.$, Oakey, 1982). $k_{\mathrm{BT}}=\left(\varepsilon /\left(\nu \kappa_{T}^{2}\right)\right)^{1 / 4}$, $k_{\mathrm{BS}}=\left(\varepsilon /\left(\nu \kappa_{S}^{2}\right)\right)^{1 / 4}$, and $k_{\mathrm{BTS}}=\left(\varepsilon /\left(\nu \kappa_{\mathrm{TS}}^{2}\right)\right)^{1 / 4}$, where $\kappa_{T}\left[\mathrm{~m}^{2} / \mathrm{s}\right]$ and $\kappa_{S}\left[\mathrm{~m}^{2} / \mathrm{s}\right]$ are the molecular diffusivities for temperature and salt, and $\kappa_{\mathrm{TS}}=\left(\kappa_{T}+\kappa_{S}\right) / 2$. The dissipation rates of temperature and salinity variance are given by $\chi_{T}$ $=2 \Gamma \varepsilon N^{-2}(\overline{d T / d z})^{2}\left[\mathrm{~m}^{2} / \mathrm{s}\right]$ and $\chi_{S}=2 \Gamma \varepsilon N^{-2}(\overline{d S / d z})^{2}\left[\mathrm{~m}^{2} / \mathrm{s}\right]$, where $\Gamma=0.2$ is the mixing efficiency (Gregg, 1987), $N$ is the buoyancy frequency $\left(N^{2}=-g / \rho \partial \rho / \partial z, g\right.$ is the acceleration due to gravity), and $\overline{d T / d z}$ and $\overline{d S / d z}$ are the vertical temperature and salinity gradients averaged over $1 \mathrm{~m}$ intervals.

\section{Weakly scattering fluid-like zooplankton}

The scattering models and parameters used in this study for weakly scattering fluid-like zooplankton are summarized in Table I. A scattering model based on the distorted-wave Born approximation (DWBA) (Stanton et al., 1998a, b; Stanton and Chu, 2000) is used for most of these zooplankton for all frequencies and angles of orientations. It is adequate to model the shape of many elongated fluid-like zooplankton as uniformly bent and tapered cylinders or prolate spheroids averaged over a distribution of angles (Stanton and Chu, 2000). Though there have been a number of studies aimed at quantifying typical angular distributions (Kils, 1981; Chu et al., 1993; Endo, 1993; Miyashita et al., 1996; McGehee et al., 1998; Benfield et al., 2000; Lawson et al., 2006) and material properties for certain zooplankton (Foote, 1990; Chu et al., 2000, 2003; Chu and Wiebe, 2005), these factors continue to result in great uncertainty in predicting scattering from many fluid-like zooplankton.

\section{Elastic-shelled zooplankton}

Elastic-shelled zooplankton, such as thecosome (i.e., shelled) pteropods, can give rise to high scattering levels compared to fluid-like zooplankton of a similar size (Stanton et al., 1994). Pteropods have hard, rough, spiral, elastic, aragonite shells, with a large discontinuity called the opercular opening. The shelled pteropod found most commonly in the GoM, Limacina retroversa, is modeled as being spherical in shape as it generally supports only a slight elongation (length-to-width ratio $\beta_{D}<3$ ). As water-column zooplankton are close to neutrally buoyant, pteropod shells are generally quite thin, potentially as thin as a few micrometers (Lalli and Gilmer, 1989). Little is known regarding the in situ swimming orientation of many pteropods, though there is evidence that they tend to swim preferentially with the opercular opening facing up (Gallager et al., 1996), which could result in differences between volume backscattering measurements with upward- and downward-facing acoustic systems.

The only published scattering models for elastic-shelled zooplankton have been developed by Stanton and colleagues (Stanton et al., 1994, 1998a, b, 2000). Stanton et al. (1994) collected laboratory scattering data for individual pteropod shells and found that a high-pass dense fluid-sphere model with an empirically derived reflection coefficient $(R=0.5)$ best fit the data. This model is commonly used in the literature, yet the reflection coefficient is lower than the value based on the actual material properties for aragonite $(g=2.84, h=3.98 ; R=0.84)$.

In later studies, Stanton et al. (1998b, 2000) developed ray-based scattering models that incorporated subsonic zeroth-order antisymmetric Lamb waves and the effects of shell roughness. However, these models are valid for $k a>1$ and include a number of heuristic parameters that are unknown for the current study, and thus are inappropriate for the current study for which $k a=0.03-2.5$. Finally, Stanton et al. (2000) were able to reproduce averaged scattering data for elastic-shelled gastropods (benthic organisms similar in shape to pteropods) by using an averaged model based on an 
TABLE I. Scattering models and associated model parameters used to predict high-frequency acoustic scattering from different fluid-like zooplankton. The DWBA uniformly-bent cylinder model was used for the majority of elongated fluid-like zooplankton (Eq. (6) in Stanton et al., 1998b; Eq. (6) in Stanton and Chu, 2000). A slight tapering (taper parameter=10) was applied to the cylinder ends (Eq. (2) in Lawson et al., 2006, following Chu et al., 1993). As the scattering is not particularly sensitive to the length-to-radius-of-curvature ratio $\left(\rho_{\mathrm{L}}\right)($ Stanton et al., 1993$), \rho_{\mathrm{L}}=3$ is used throughout this study. Averages were performed over a normal distribution of angles of orientation, with the mean and standard deviation determined from the literature when possible. As the in situ angular distribution is not known for most zooplankton taxa, unless otherwise stated, a mean of $0^{\circ}$ (corresponding to broadside incidence or horizontally oriented) and a standard deviation of $30^{\circ}$ was used. In some cases, the model parameters have been validated through comparison with laboratory or in situ measurements. All lengths (L) in the table are in millimeters. The length-to-width ratio, $\beta_{D}$, should not be confused with the length-to-radius ratio, $\beta$, used by Stanton et al. (1998b).

\begin{tabular}{|c|c|c|c|c|}
\hline $\begin{array}{l}\text { Taxon } \\
\text { (Scattering model) }\end{array}$ & $\begin{array}{l}\text { Length-to-width ratio } \\
\qquad\left(\beta_{D}\right)\end{array}$ & $\begin{array}{c}\text { Orientation } \\
\text { (Mean, STD) }\end{array}$ & Density contrast (g) & Sound speed contrast (h) \\
\hline $\begin{array}{l}\text { Euphausiids and Decapod Shrimp } \\
\text { (DWBA uniformly-bent cylinder) }\end{array}$ & $10.5^{\mathrm{a}}$ & $\mathrm{N}(20,20)^{\mathrm{b}, \mathrm{R} 1}$ & $\begin{array}{c}g=5.485 L / 10^{4}+1.002, \quad L>25 \\
g=1.016, \quad L<25^{\mathrm{R} 2}\end{array}$ & $\begin{array}{c}h=5.942 L / 10^{4}+1.004, \quad L>25 \\
h=1.019, \quad L<25^{\mathrm{R} 2}\end{array}$ \\
\hline $\begin{array}{l}\text { Larval Crustaceans }{ }^{c} \\
\text { (DWBA uniformly-bent cylinder) }\end{array}$ & $2.55^{\mathrm{d}}$ & $\mathrm{N}(0,30)$ & $1.058^{\mathrm{R} 3}$ & $1.058^{\mathrm{R} 3}$ \\
\hline $\begin{array}{l}\text { Amphipods }{ }^{\mathrm{c}, \mathrm{R} 4} \\
\text { (DWBA uniformly-bent cylinder) }\end{array}$ & $3.00^{\mathrm{d}}$ & $\mathrm{N}(0,30)$ & $1.058^{\mathrm{R} 3}$ & $1.058^{\mathrm{R} 3}$ \\
\hline $\begin{array}{l}\text { Ostracods }{ }^{\mathrm{c}} \\
\text { (DWBA uniformly-bent cylinder) }\end{array}$ & $2.55^{\mathrm{d}}$ & $\mathrm{N}(0,30)$ & $1.03^{\mathrm{R} 5}$ & $1.03^{\mathrm{R} 5}$ \\
\hline $\begin{array}{l}\text { Chaetognaths and Polychaetes } \\
\text { (DWBA uniformly-bent cylinder) }\end{array}$ & $17.15^{\mathrm{d}}$ & $\mathrm{N}(0,30)$ & $1.03^{\mathrm{R} 5}$ & $1.03^{\mathrm{R} 5}$ \\
\hline $\begin{array}{l}\text { Gymosome Pteropods }(\text { Clione })^{\mathrm{c}} \\
(\text { DWBA uniformly-bent cylinder })\end{array}$ & $1.83^{\mathrm{d}}$ & $\mathrm{N}(0,30)$ & $1.03^{\mathrm{R} 5}$ & $1.03^{\mathrm{R} 5}$ \\
\hline $\begin{array}{l}\text { Salps }{ }^{\mathrm{c}, \mathrm{R} 6, \mathrm{R} 7} \\
(\text { DWBA uniformly-bent cylinder })\end{array}$ & $4.0^{\mathrm{d}}$ & $\mathrm{N}(0,30)$ & $1.004^{\mathrm{R} 6}$ & $1.004^{\mathrm{R} 6}$ \\
\hline $\begin{array}{l}\text { Copepods } \\
\left(D W B A \text { prolate spheroid }{ }^{\mathrm{R} 10}\right)\end{array}$ & $2.55^{\mathrm{d}}$ & $\mathrm{N}(90,30)^{\mathrm{e}, \mathrm{R} 8}$ & $1.02^{\mathrm{R} 5}$ & $1.058^{\mathrm{R} 9}$ \\
\hline $\begin{array}{l}\text { Medusae }^{\mathrm{R} 11} \\
\left(\text { DWBA two prolate spheroidal surfaces }{ }^{\mathrm{R} 5} \text { ) }\right.\end{array}$ & NA & NA & $1.02^{\mathrm{f}}$ & $1.02^{\mathrm{f}}$ \\
\hline $\begin{array}{l}\text { Eggs } \\
\left.\text { (High-pass fluid sphere }{ }^{\mathrm{g}, \mathrm{R} 13}\right)\end{array}$ & NA & NA & $0.979^{\mathrm{R} 12}$ & $1.017^{\mathrm{R} 12}$ \\
\hline
\end{tabular}

R1: Chu et al., 1993

R2: Lawson et al., 2004

R3: Table I in Lawson et al. (2004)

R4: Trevorrow and Tanaka, 1997

R5: Personal communication Dezhang Chu

R6: Stanton et al., 1994

R7: David et al., 2001

R8: Benfield et al., 2000

R9: Chu et al., 2000

R10: Fig. 12 in Stanton and Chu, 2000

R11: Mutlu, 1996; Monger et al., 1998; Brierley et al., 2004

R12: Chu et al., 2003

R13: Stanton, 1989

${ }^{a}$ Measurements performed by Joe Warren (personal communication) for a subset of euphausiids in Wilkinson Basin in the GoM in October 1999. This value is larger by almost a factor of 2 than values used previously in the literature (Warren et al., 2003; Fielding et al., 2004) leading to significant decreases in the predicted scattering.

${ }^{\mathrm{b}} \mathrm{A}$ recent study has indicated that the distribution of euphausiid orientations in the Western Antarctic Peninsula has a mean that is close to $0^{\circ}$ (Lawson et al., 2006). This change results in small changes in the contribution to scattering from euphausiids and does not affect the conclusions arrived at here, particularly as euphausiids did not greatly contribute to the predicted scattering in the GoM. In addition, the changes of the measured pitch and roll of BIOMAPER-II were sufficiently small that they do not significantly affect the scattering predictions for euphausiids, or any other zooplankton.

${ }^{c}$ There have been limited acoustic studies specific to these zooplankton and the DWBA uniformly-bent cylinder model was used as they have no known gas inclusions and their material properties appear similar to those of better studied fluid-like zooplankton.

${ }^{\mathrm{d}}$ These length-to-width ratios were based on measurements of a sub-sample of zooplankton from the Western Antarctic Peninsula (Table I of Lawson et al., 2004). It is expected that these parameters will depend on season and geographic location.

${ }^{\mathrm{e}}$ Other studies have used a normal distribution of orientations for copepods with a mean of $0^{\circ}$ (broadside incidence or horizontally oriented) and a standard deviation of $30^{\circ}$ (Lawson et al., 2004). This distribution was also investigated, but due to the averaging the differences in the predicted scattering between the two distributions of orientations were small and did not affect the conclusions of this study.

${ }^{\mathrm{f}}$ Inferred from comparison of the Monger et al. (1998) data to the model predictions, personal communication Dezhang Chu.

${ }^{\mathrm{g}} \sigma_{b s}=a^{2}(k a)^{4} \alpha_{\pi s}^{2} /\left(1+4(k a)^{4} \alpha_{\pi s}^{2} / R^{2}\right)$ where $\alpha_{\pi s}=\left(1-g h^{2}\right) / 3 g h^{2}+(1-g) /(1+2 g)$ and $R=(g h-1) /(g h+1)$.

idealized spherical fluid-filled elastic shell, which has an exact modal series solution (Goodman and Stern, 1962) and is valid for all $k a$, where the average is over a range of radii and shell thickness (Fig. 11 in Stanton et al., 2000).
Three different models for elastic-shelled pteropods were used in this study (Fig. 2). MODEL 1: A high-pass dense fluid-sphere model (in Table I) with $g=h=1.73$ and $R=0.5$. This model best fits the Stanton et al. (1998a: Fig. 4) 


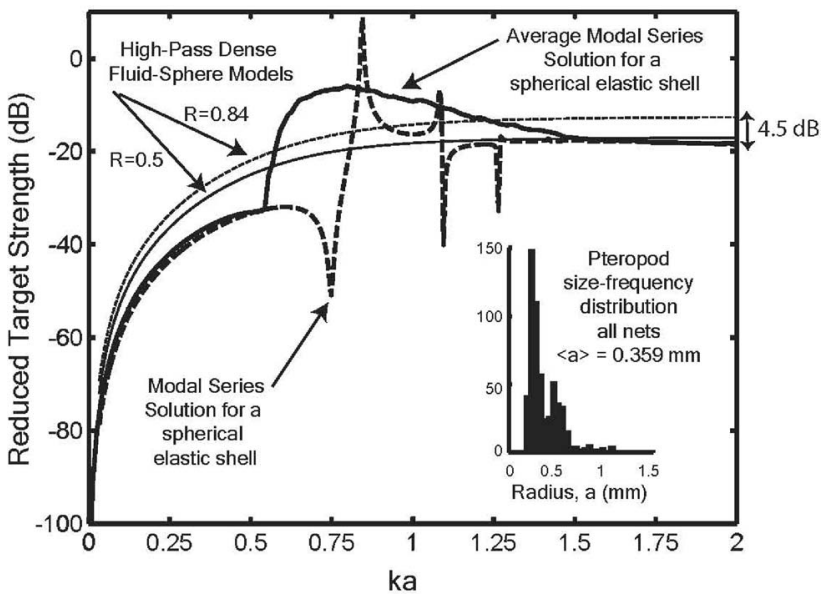

FIG. 2. Reduced target strength (RTS) for elastic-shelled pteropods as a function of $k a$ based on the high-pass dense fluid-sphere model with $R$ $=0.5$ (thin solid line) and $R=0.84$ (thin dashed line), the exact modal series solution for an individual spherical aragonite shell (thick dashed line) with a fractional shell thickness (shell thickness/mean radius) of $2.3 \%$, corresponding to shell thicknesses of 4-9 $\mu \mathrm{m}$ for the range of measured pteropod radii in the GoM, and an averaged modal series solution for a spherical aragonite shell, with the average taken over a Gaussian distribution of shell radii and thickness (thick solid line). The value for the fractional shell thickness is consistent with those found in the literature (Lalli and Gilmer, 1989; Chu and Stanton, 1998), as well as with restricted measurements performed by the authors for crushed shell parts. For large values of $k a$, the difference in the reduced target strength predicted by the high-pass dense fluid-sphere model with reflection coefficients $R_{1}$ and $R_{2}$ is $10 \log _{10}\left(R_{1}^{2} / R_{2}^{2}\right)$, or $4.5 \mathrm{~dB}$ for $R_{1}=0.5$ and $R_{2}=0.84$. For these predictions, the density contrast between the surrounding water and the shell was 2.84 and 1.022 between the surrounding water and the fluid interior. The compressional sound speed contrasts between the surrounding water and the shell and fluid interior were 3.98 and 1.04, respectively. The shear sound speed contrast was 2.34. The averages were performed over a Gaussian distribution of shell radii with a $20 \%$ standard deviation (s.d.), and a Gaussian distribution of shell thickness centered around a fractional shell thickness of $2.3 \%$ and with a $10 \%$ s.d., spanning \pm 2 s.d. from the mean (the approach taken by Stanton et al., 2000). These parameters were chosen to give a reasonable fit to published values of the average RTS, $-18.2 \mathrm{~dB}$ over a range of $k a$ values from 1.16 to 1.88 , deduced from laboratory measurements of scattering from pteropods (Fig. 4 in Stanton et al., 1998a). The inset shows the size-frequency distributions for all pteropods observed in the GoM.

pteropod data when averaged over all angles of orientation. MODEL 2: A high-pass dense fluid-sphere model with $g$ $=2.84$ and $h=3.98$ for aragonite, for which $R=0.84$. MODEL 3: An averaged exact modal series solution for a fluid-filled elastic aragonite shell (following Stanton et al., 2000).

Finally, there are other zooplankton with hard elastic shells, including foraminifera and radiolarians. These zooplankton are more complex and irregular in shape than pteropods, are typically an order of magnitude smaller, and can have shells made of aragonite, calcite, or silica. A high-pass dense fluid-sphere model was used for these zooplankton with $g=2.147$ and $h=3.979$ based on values for fused silica.

\section{E. Gas-bearing zooplankton}

Siphonophores are fragile gelatinous zooplankton that often possess small gas inclusions called pneumatophores. The siphonophore most commonly observed in the GoM, Nanomia cara, typically has a single pneumatophore filled with carbon monoxide gas $(g=0.0012$ and $h=0.22)$ (Benfield et al., 2003, and references therein). The nongaseous weakly scattering tissue of the siphonophores is composed of numerous gelatinous parts, including nectophores and bracts. Scattering by the pneumatophores is significantly stronger than the scattering from the tissue over a broad frequency range (Fig. 5 in Stanton et al., 1998a, Warren et al., 2001), particularly at the resonance frequency of the gas inclusion.

In this study, a hybrid scattering model for a fluid-filled sphere has been used for the siphonophore pneumatophores in which a simple model that includes damping was used for $k a<0.1$, and the exact modal series solution for a fluid sphere (Anderson, 1950) was used for $k a>0.1$. For $k a$ $<0.1$ the backscattering cross section is given by (Weston, 1967)

$$
\sigma_{\mathrm{bs}}=\frac{a^{2}}{\left(1-k_{0}^{2} / k^{2}\right)^{2}+1 / Q^{2}},
$$

where $a$ is the bubble radius and $k_{0}$ is the acoustic wave number at the resonance frequency, given by

$$
k_{0}=\frac{(3 \gamma)^{\frac{1}{2}}}{a c}\left(\frac{P_{0}(1+0.1 z)}{\rho}\right)^{\frac{1}{2}},
$$

where $z$ is depth, $\rho=1027 \mathrm{~kg} / \mathrm{m}^{3}, P_{0}=1.013 \times 10^{5} \mathrm{~Pa}$ is the pressure at the surface, and $\gamma(\gamma=1.4)$ is the ratio of gaseous specific heats. $Q$ is the quality factor $\left(Q=\delta^{-1}\right.$, where $\delta$ is the damping constant). A typical value for swim-bladdered fish is $Q=5$ (Diachok, 2001), and for lack of data, it was also assumed here that $Q=5$. The depth dependence has been included by assuming a sphere of constant volume (Benfield et al., 2003). This damped model is only valid at small $k a$ as an inherent assumption is that the scattering is spherically symmetric. At high $k a$ values, the total scattering cross section, $\sigma$, for an ideal gas-filled sphere should be independent of frequency (ignoring narrow resonances) and converge to the geometrical scattering cross section $\left(\pi a^{2}\right)$. Yet for the damped model, $\sigma$ converges to $4 \pi a^{2}$, a factor of $4(\sim 6 \mathrm{~dB})$ too large. The difference between the damped model and the exact modal series solution is larger than $5 \%$ for $k a>0.1$. As the range of $k a$ values spanned in this study is 0.0034-3.99, the hybrid approach was necessary.

The exact modal series solution for a fluid sphere ( $g$ $=h=1.02$ ) was also used to describe the scattering from siphonophore body parts. Lengths were converted to radii of the spheres of equivalent volume using an empirically derived scaling factor $\left(L=\gamma a_{\mathrm{esr}}\right.$, where $\gamma=0.4$ for nectophores and $\gamma=0.29$ for bracts). These scaling factors were derived for siphonophore body parts collected in the Western Antarctic Peninsula (Lawson et al., 2004), and could differ according to siphonophore genera and location. In previous work (Stanton et al., 1998b) siphonophore body parts have also been modeled as cylinders. The contributions to scattering from the siphonophore pneumatophores and body parts were added incoherently. Though siphonophore parts are weakly scattering, their dimensions are relatively large compared to more abundant copepods or pteropods (mean measured length for bracts $=8.2 \mathrm{~mm}$, with individuals as large as $19.5 \mathrm{~mm}$ ). As a result, the Rayleigh-to-geometric scattering transition occurs at lower frequencies for siphonophore body parts than for copepods or pteropods. Thus, over the range of 
frequencies for which the large siphonophore body parts have reached the geometric scattering regime but more abundant, smaller zooplankton have not, the contribution to scattering from siphonophore body parts can be larger than the contribution from copepods or pteropods, even when the siphonophores occur in relatively low abundances.

\section{F. Other sources of scattering}

In this study, scattering from organisms that were rarely observed in the net samples, including fish and fish larvae (ten individuals observed in all 56 nets, only one myctophid), starfish (nine individuals), crabs (two individuals), and bivalves (one individual), has not been included. Scattering from diatoms was also omitted, as they were small (average length $0.3 \mathrm{~mm}$ ) and only observed at some locations with low abundances. Scattering from bubbles can be also important close to the surface, potentially dominating the scattering over a wide range of frequencies. As there was no method of quantifying the bubble size distribution close to the surface, analysis of the surface scattering layer was not included in this study. While suspended sediments are also known to contribute to water-column scattering over the shallow waters of Georges Bank (Wiebe et al., 1997; Pershing et al., 2001), no suspended sediment was observed in the deep basins of the GoM, and thus it is not included in forthcoming analyses.

\section{METHODS}

The results presented here involve the collection of nearcoincident multi-frequency acoustic data, net tows, CTD profiles, and video images of zooplankton. Central to the program is the towed instrument platform BIOMAPER-II that collects along-track video images of plankton and multifrequency acoustic backscattering (Fig. 1). Additional ground truthing is provided by CTD profiles and depthresolved oblique net tows. The methods used to collect and analyze data collected with these instruments are outlined in this section, together with a description of how this information is combined with the scattering models to make volume scattering predictions.

\section{A. BIOMAPER-II towed instrument platform}

BIOMAPER-II is specifically designed to conduct synoptic, high-resolution, multi-frequency zooplankton acoustic surveys (Wiebe et al., 2002). The key components of this instrument are the five upward- and five downward-looking transducers $(43,120,200,420$, and $1000 \mathrm{kHz})$, manufactured by Hydroacoustic Technologies Inc. (HTI, Seattle, WA), a single camera Video Plankton Recorder (VPR) (Davis et al., 1992), and sensors for measuring temperature, conductivity, pressure, heading, pitch, and roll. Full watercolumn acoustic coverage in shelf waters can often be achieved at the four lower frequencies with BIOMAPER-II at depth since each pair of acoustic transducers has one downward- and one upward-facing transducer. BIOMAPER-II is normally towed in an undulating fashion, up and down through the water column, from a few meters below the sea surface to within 10 or $20 \mathrm{~m}$ from the seafloor, in order to collect VPR images and environmental data at all depths. A Global Positing System (GPS) receiver synchronized the different data. BIOMAPER-II is typically towed at speeds of 4-7 knots, except when biological net samples are collected and the tow speed is below 2.5 knots.

Volume backscattering is collected from sequential transmissions from all ten transducers in $1 \mathrm{~m}$ depth intervals to a range of $200 \mathrm{~m}$ at 43 and $120 \mathrm{kHz}, 150 \mathrm{~m}$ at $200 \mathrm{kHz}$, $100 \mathrm{~m}$ at $420 \mathrm{kHz}$, and $35 \mathrm{~m}$ at $1 \mathrm{MHz}$. The $1 \mathrm{MHz}$ backscattering data are not used in this study due to their reduced range. A $10 \mathrm{kHz}$ bandwidth, linear frequency modulated (chirp) signal was used at a repetition rate of $2.5 \mathrm{pings} / \mathrm{s}$. Echo integration was performed every $12 \mathrm{~s}$ to obtain volume backscattering, corresponding to a horizontal resolution of approximately $30-40 \mathrm{~m}$, depending on vessel speed. Combined noise levels resulting from the ship, ambient, and system noise, were collected as a function of depth with BIOMAPER-II in "passive listening" mode. Noise thresholds, which vary with range and frequency (Korneliussen, 2000 ), were set by adding $6 \mathrm{~dB}$ to the measured noise profiles. Backscattering levels were then compared to these noise thresholds on a ping-by-ping basis, prior to echo integration, and bins in which the backscattering did not exceed the noise were set to zero. The transducers were split-beam and had full beamwidths $(-3 \mathrm{~dB}$ to $-3 \mathrm{~dB})$ of $7^{\circ}$ for the $43 \mathrm{kHz}$ and $3^{\circ}$ for the $120-420 \mathrm{kHz}$. The corresponding sampling volumes of a 1-m-thick bin centered at $100 \mathrm{~m}$ ranged from 21 to $86 \mathrm{~m}^{3}$.

The acoustic system on BIOMAPER-II was calibrated by HTI in September 1999, immediately prior to this study, using both standard transducers and standard targets, for source level, receive sensitivity, and beam patterns. These calibrations were supplemented with standard-target calibrations, using 20 and $38.1 \mathrm{~mm}$ tungsten carbide (6\% cobalt) spheres and excluding off-axis returns, performed at Woods Hole Oceanographic Institution (WHOI) based on the practices established by Foote et al. (1987). Depth-dependent calibrations were not performed, but the transducer backings were made of a noncompressible synthetic material to minimize the effect of depth-dependent changes in the transducer performance. In addition, changes in the scattering from the sea floor as a function of BIOMAPER-II depth, down to approximately $200 \mathrm{~m}$, were small, generally smaller than $0.5 \mathrm{~dB}$, which will not affect the conclusions arrived at in this study. Studies performed by Kloser (Fig. 2 in Kloser, 1996) and Gauthier and Rose (Fig. 4 in Gauthier and Rose, 2002) support the conclusion that depth-dependent changes in transducer calibrations with this type of backing will not be significant over the range of depths investigated here. Futhermore, for the majority of the data analyzed in this paper, which involve data dollected when BIOMAPER-II was towed at the surface during the net tows, there are no depthdependent effects that need to be considered.

A region of enhanced backscattering was observed in the vicinity of BIOMAPER-II, particularly at 43 and $120 \mathrm{kHz}$, while BIOMAPER-II was towed up and down through the water column at depths with strong gradients in the temperature and salinity. Regions in which enhanced backscattering were observed are not used in a quantitative way in this 
study: the enhancement was not observed during the net tows when BIOMAPER-II was towed at the surface.

\section{B. Physical and biological sampling 1. Physical sampling}

The ship's CTD (Sea Bird 911 plus), sampling at $24 \mathrm{~Hz}$, with typical descent rates of $1 \mathrm{~m} / \mathrm{s}$, was used to determine many of the parameters needed to make predictions of scattering from microstructure. Though BIOMAPER-II collected physical environmental data, as it was towed up and down through the water column, calculation of vertical gradients would need to account for horizontal gradients. In addition, the sampling rate was low $(0.25 \mathrm{~Hz})$, corresponding to at best $6-8 \mathrm{~m}$ horizontal resolution and $40 \mathrm{~cm}$ vertical resolution.

\section{Biological sampling: Nets}

Depth-resolved zooplankton samples were collected at select locations using a $1-\mathrm{m}^{2}$ Multiple Opening/Closing Net and Environmental Sensing System, MOCNESS (Wiebe et al., 1985). The MOCNESS system was towed obliquely while the BIOMAPER-II instrument was at the surface collecting acoustic data. The MOCNESS was equipped with nine $335 \mu \mathrm{m}$ mesh nets and environmental sensors including a flow meter, temperature, conductivity, and depth. The first net (net 0) sampled the entire water column down to approximately $10 \mathrm{~m}$ above the bottom, and the remaining eight nets sampled quantitatively, with sampling strata dependent on the water depth: typically, the upper $100 \mathrm{~m}$ was sampled in $25 \mathrm{~m}$ intervals, with a few $50 \mathrm{~m}$ intervals at intermediate depths, and $25 \mathrm{~m}$ intervals at the deeper depth ranges. The samples were preserved upon recovery in 5\% buffered formalin. The "silhouette" method developed by Ortner et al. (1979) and modified by Davis and Wiebe (1985) was used to measure the size (typically length) of each individual organism in each net sample. Between 100 and $300 \mathrm{~m}^{3}$ of water were filtered by each net. Occasionally, the number of organisms in a particular net was excessively large, making it unfeasible to count every individual. These large samples were sequentially split into two equal portions, sometimes more than once.

\section{Biological sampling: Video images}

The VPR is a high-magnification underwater video system that records images of plankton using an analog video camera and strobe light (Davis et al., 1992), and is mounted to the front end of the BIOMAPER-II instrument. The volume imaged by this system is $5.1 \mathrm{ml}$ at $60 \mathrm{~Hz}$ (3 $\times 10^{-4} \mathrm{~m}^{3} / \mathrm{s}$ ), many times smaller than the acoustic or MOCNESS sampling volumes. The postprocessing of the images involved digitization and target detection using userdefined criteria for size, focus, and brightness (Benfield et al., 2003). Targets that met these criteria were sorted into different taxonomic categories, enumerated and measured together with the location, time, and depth at which they were observed. For copepods, the size measured in the video images was the smallest dimension, which corresponds approximately to the width of the organisms. The length of the copepods was then determined using the length-to-width ratio $\beta_{D}=2.55$. This approach was taken to minimize the effect of ambiguities in the orientation of individual copepods in the field of view of the camera.

\section{Predicting volume backscattering: The forward calculation \\ 1. Predicting volume backscattering from turbulent microstructure}

The predicted volume backscattering for turbulent microstructure was based on Eq. (2) (Sec. II B), with all the necessary model parameters determined from the CTD data except the dissipation rate of turbulent kinetic energy, $\varepsilon$. Many of the model parameters, such as $A$ and $B$, are relatively constant as a function of depth and their depthaveraged values were used. Temperature and salinity gradients and the buoyancy frequency were averaged over $1 \mathrm{~m}$ depth bins. The CTD profiles were carefully processed to remove spikes in the temperature and salinity gradients resulting from the heaving motion of the vessel. Measurements of $\varepsilon$ typically require specialized microstructure instruments, which were not available in this study. Under some circumstances it is possible to determine $\varepsilon$ by identifying the outer scales of overturning eddies from CTD profiles (Thorpe, 1977). However, in regions of weak density gradients, low dissipation rates, and high sea states, the inferred values of $\varepsilon$ can be compromised. Instead of pursuing this approach, an upper-bound estimate for $\varepsilon\left(\varepsilon=10^{-6} \mathrm{~m}^{2} / \mathrm{s}^{3}\right)$ based on available information in the published literature (Burgett et al., 2001) was used to estimate an upper-bound contribution to scattering from microstructure at each location and depth. The actual contribution to scattering from microstructure is expected to be lower than the upper-bound prediction.

\section{Predicting volume backscattering from zooplankton: Nets}

The predicted volume backscattering based on the MOCNESS samples was calculated using Eq. (1) at the four BIOMAPER-II frequencies $\left(f_{q}=43,120,200\right.$, and $\left.420 \mathrm{kHz}\right)$, and at each of the eight MOCNESS depth ranges, $d_{k}$, where $k$ varies from 1 to 8 . The backscattering cross section was calculated for each individual organism sampled by the MOCNESS based on its measured length. Though no differences are expected in the scattering from upward- versus downward- facing transducers for any weakly scattering zooplankton (Lavery et al., 2001), this may not be the case for elastic-shelled zooplankton. However, as BIOMAPER-II was towed at the surface during the MOCNESS tows, only acoustic data from the downward-looking transducers are used for comparisons of predicted and observed scattering. For the comparison of measured and predicted volume backscattering, the measured volume backscattering was averaged over the same time intervals and range of depths as were sampled by each of the MOCNESS nets in a given profile. The offset between the MOCNESS and the BIOMAPER-II was not accounted for as it was no larger than $200 \mathrm{~m}$ and, at select locations where the offset was accounted for, it did not significantly affect the results. The 

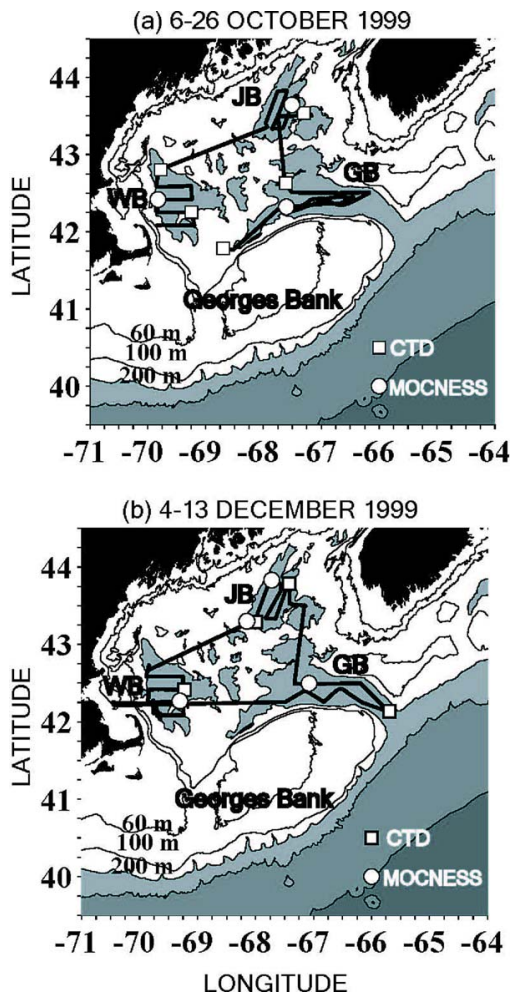

FIG. 3. (Color online) (a) October and (b) December, 1999, actual survey tracks superimposed on the bathymetry of the Gulf of Maine (GoM). The location of the three major basins in the GoM, Wilkinson Basin (WB), Jordan Basin (JB), and Georges Basin (GB) are indicated. The squares show the locations of the CTD profiles and the circles show the locations of the MOCNESS tows. Gale conditions in Georges Basin in October, 1999, resulted in significant deviations from the planned survey grid lines, in addition to BIOMAPER-II having to be towed at a depth of $100 \mathrm{~m}$ for large distances.

scattering predictions for the shallowest MOCNESS nets (nets 8), spanning the top $25 \mathrm{~m}$ of the water column, were not compared to the measured scattering in this depth range, though predictions were made, since elevated scattering was often observed, probably due to bubbles generated by breaking waves or the ship's wake, and it was not possible to quantitatively evaluate their contribution to the observed scattering.

\section{Predicting volume backscattering from zooplankton: Video images}

Predictions of volume backscattering based on the VPR images proceeded in much the same way as for the MOCNESS. However, as the acoustic data were averaged over $1 \mathrm{~m}$ depth bins, the predicted volume backscattering based on Eq. (1) and the VPR images were also binned into $1 \mathrm{~m}$ depth bins. The VPR images from the upward and downward parts of the tow were combined, and the acoustic data were averaged horizontally across the duration of the tow.

\section{GENERAL OBSERVATIONS IN THE GULF OF MAINE}

Selected results are presented from two acoustic surveys of the deep basins of the Gulf of Maine (GoM) performed with the BIOMAPER-II towed instrument platform during (a) JORDAN BASIN: 20-21 OCTOBER 1999

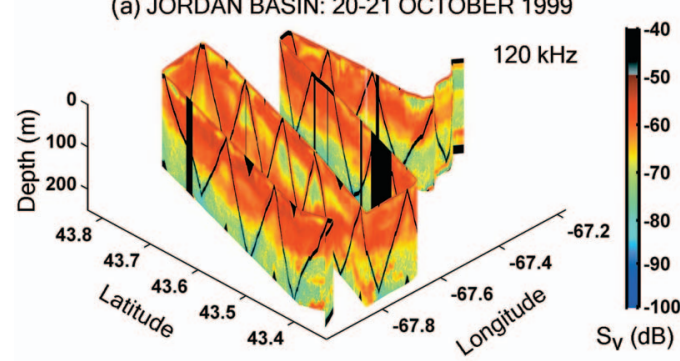

(b) JORDAN BASIN: 6-7 DECEMBER 1999

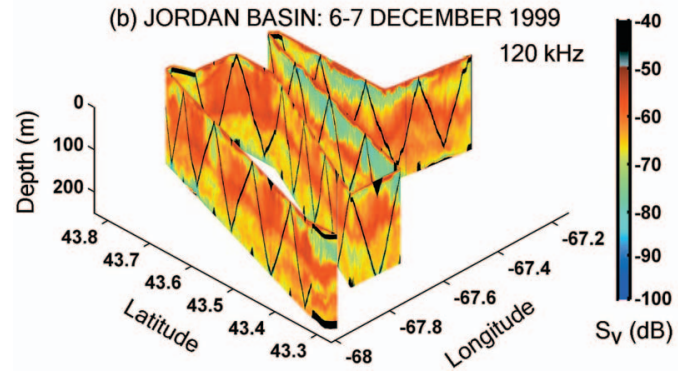

FIG. 4. Volume backscattering at $120 \mathrm{kHz}$ as a function of depth, latitude and longitude in Jordan Basin, GoM, during (a) October and (b) December 1999. The black line is the BIOMAPER-II trajectory.

16-26 October (cruise EN330) and 4-13 December (cruise EN331), 1999, on board the RV Endeavor (Fig. 3). Hundreds of kilometers of along-track acoustics data and associated direct physical and biological data were collected in the three deep basins in the GoM: Wilkinson (WB), Jordan (JB), and Georges (GB), each with typical depths between 200 and $300 \mathrm{~m}$.

\section{A. Acoustical observations}

The volume scattering strength during the 1999 surveys of the deep basins of the GoM was characterized by a complex horizontal and vertical structure, with spatial structures observed over a range of different scales, from a few meters to tens of kilometers (Fig. 4). At many locations the scattering increased monotonically with increasing frequency. At some locations and depths, such as the pervasive scattering layer that was often observed at the seasonal thermocline (Brooks, 1996) (Fig. 5), the scattering varied nonmonotonically with frequency, largest at $120 \mathrm{kHz}$, smallest at $43 \mathrm{kHz}$, and broadly similar at 200 and $420 \mathrm{kHz}$. High scattering levels were observed close to the sea surface, probably due to bubbles. A deeper scattering layer was observed occasionally, typically during daylight hours, and the volume scattering associated with this deeper layer was approximately constant at all frequencies.

\section{B. Physical observations}

At least one CTD profile was performed in each basin during the October and December 1999 surveys (Table II). The seasonal thermocline was located at approximately 40-60 $\mathrm{m}$ in October and 70-100 $\mathrm{m}$ in December 1999. The temperature and salinity stratification in the early fall was significantly larger than in the late fall, particularly in Wilkinson Basin. 

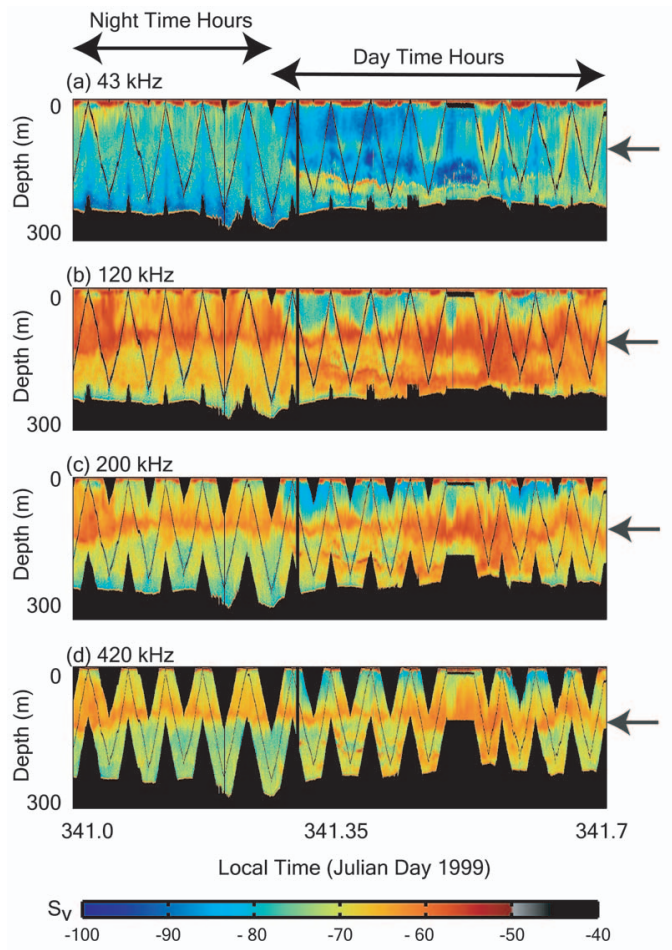

FIG. 5. Volume backscattering as a function of depth and local time on 7 December 1999 in Jordan Basin, GoM, showing the frequency dependence of the daily vertical migration of zooplankton. The arrows on the right indicate the approximate depth of the seasonal thermocline, which was located at approximately $40-60 \mathrm{~m}$ in October and 70-100 m in December The diel migration of zooplankton was observed all frequencies. The largest differences between the day and night scattering were observed at $43 \mathrm{kHz}$, particularly for the deeper scattering layer.

\section{Biological observations \\ 1. Biological observations: Nets}

One night tow per basin has been analyzed for taxon composition and size distribution for each survey, in addition to a day tow in Jordan Basin in December 1999 (Table III, Fig. 3). Copepods made up the majority of the numerical abundance (Fig. 6) and biomass (Fig. 7) of zooplankton at most locations. Euphausiids contributed most significantly to biomass in December 1999 in Wilkinson and Georges Basin. Other weakly scattering zooplankton only contributed significantly to biomass at select locations. Pteropods made up an insignificant portion of the observed biomass at any location, while the biomass due to siphonophores was only significant at a few locations.

It is difficult to accurately assess the distribution and abundance of siphonophores as they are often overlooked or destroyed by net systems. However, siphonophore parts, including pneumatophores, nectophores, and bracts, were observed in most of the MOCNESS samples. There were only four nets (nets 1, 3, 6, and 8) in Wilkinson Basin in October and one net (net 1) in Jordan Basin in December in which no pneumatophores were observed. The vertical distribution of pneumatophores peaked at depths that corresponded to the seasonal thermocline, with abundances of 3-5 pneumatophores $/ \mathrm{m}^{3}$ (Fig. 8).

A number of previous studies have assumed that all observed siphonophores have pneumatophores of a single size (Warren et al., 2001, Trevorrow et al., 2005). In this study, the measured pneumatophore size distribution is used to compare observed versus predicted scattering. There is evidence based on the adult pneumatophores collected with the MOCNESS tows that the pneumatophores support a slight eccentricity, $\beta_{D}<3$, though it is unclear exactly how much

TABLE II. Dates (mm-dd-year), times, and locations of the CTD profiles performed during the October and December 1999 surveys of the deep basins of the GoM. WB=Wilkinson Basin, $\mathrm{JB}=\mathrm{Jordan}$ Basin, $\mathrm{GB}=$ Georges Basin, and $\mathrm{YD}=\mathrm{Julian}$ Year Day.

\begin{tabular}{lcccc}
\hline \hline & Local time & Local date & Latitude (N) & Longitude \\
\hline October 1999 CTD 1 (WB) & $12: 53$ (Daytime CTD) & $10-17-1999$ (YD 290) & 42.254 & -69.2412 \\
October 1999 CTD 2 (WB) & $12: 28$ (Daytime CTD) & $10-20-1999$ (YD 294) & 42.8028 & -69.7773 \\
October 1999 CTD 3 (JB) & $17: 17$ (Evening CTD) & $10-21-1999$ (YD 295) & 43.5367 & -67.2208 \\
October 1999 CTD 4 (GB) & $12: 54$ (Daytime CTD) & $10-22-1999$ (YD 296) & 42.6297 & -67.6182 \\
October 1999 CTD 5 (GB) & $11: 15$ (Daytime CTD) & $10-25-1999$ (YD 298) & 41.767 & -68.7067 \\
December 1999 CTD 1 (WB) & $14: 23$ (Daytime CTD) & $12-05-1999$ (YD 339) & 42.4128 & -69.2270 \\
December 1999 CTD 2 (JB) & $14: 35$ (Daytime CTD) & $12-06-1999$ (YD 340) & 43.2700 & -68.0007 \\
December 1999 CTD 3 (JB) & $12: 34$ (Daytime CTD) & $12-07-1999$ (YD 341) & 43.7847 & -67.4208 \\
December 1999 CTD 4 (GB) & $13: 32$ (Daytime CTD) & $12-09-1999$ (YD 343) & 42.1367 & -65.6933 \\
\hline \hline
\end{tabular}

TABLE III. Dates (mm-dd-year), times, and location of the MOCNESS tows performed during the October and December 1999 surveys of the deep basins of the GoM. WB=Wilkinson Basin, $\mathrm{JB}=$ Jordan Basin, $\mathrm{GB}=$ Georges Basin, and $\mathrm{YD}=\mathrm{Julian}$ Year Day.

\begin{tabular}{|c|c|c|c|c|c|}
\hline MOCNESS & Local time & Local date & Latitude $(\mathrm{N})$ & Longitude & Closest CTD \\
\hline MOC 2, WB, October 1999 & 01:34 (Night Tow) & 10-18-1999 (YD 291) & 42.4172 & -69.8229 & CTD 1, WB, October 1999 \\
\hline MOC 5, JB, October 1999 & 01:10 (Night Tow) & 10-21-1999 (YD 295) & 43.6426 & -67.5096 & CTD 3, JB, October 1999 \\
\hline MOC 6, GB, October 1999 & 21:44 (Night Tow) & 10-24-1999 (YD 298) & 42.3215 & -67.6027 & CTD 4, GB, October 1999 \\
\hline MOC 2, WB, December 1999 & 11:58 (Night Tow) & 12-04-1999 (YD 338) & 42.2687 & -69.3062 & CTD 1, WB, December 1999 \\
\hline MCO 4, JB, December 1999 & 13:10 (Day Tow) & 12-06-1999 (YD 340) & 43.3174 & -68.0000 & CTD 2, JB, December 1999 \\
\hline MCO 5, JB, December 1999 & 22:59 (Night Tow) & 12-06-1999 (YD 340) & 43.8303 & -67.7225 & CTD 3, JB, December 1999 \\
\hline MCO 6, GB, December 1999 & 22:55 (Night Tow) & 12-08-1999 (YD 343) & 42.4960 & -67.0767 & CTD 4, GB, December 1999 \\
\hline
\end{tabular}


NUMERICAL ABUNDANCE

(a) MOC2 (WB): NIGHT

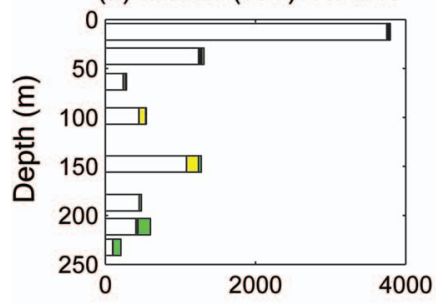

(d) MOC2 (WB):NIGHT

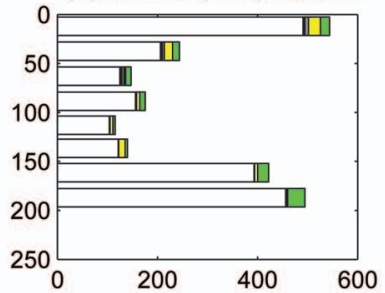

(e) MOC4 (JB): DAY

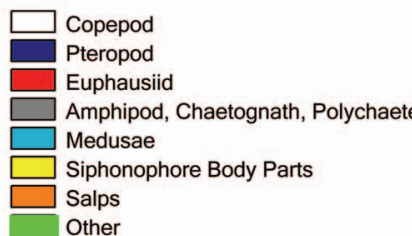

(b) MOC5 (JB): NIGHT

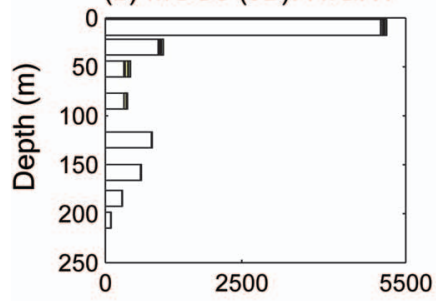

(c) MOC6 (GB): NIGHT

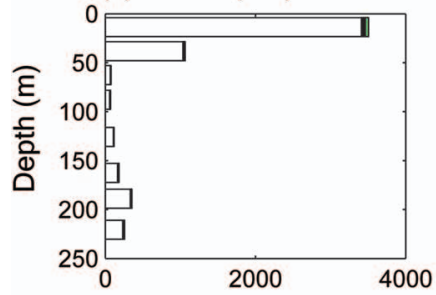

Numerical Abundance $\left(\# / \mathrm{m}^{3}\right)$ (OCTOBER 1999)

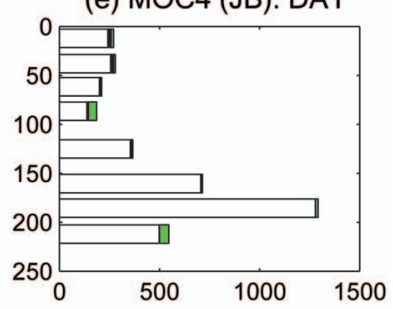

(f) MOC5 (JB): NIGHT

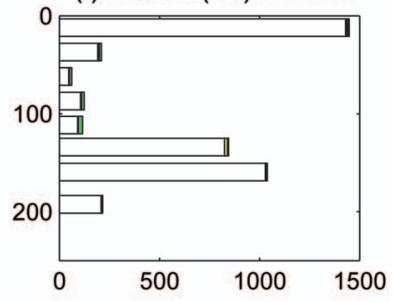

(g) MOC6 (GB): NIGHT

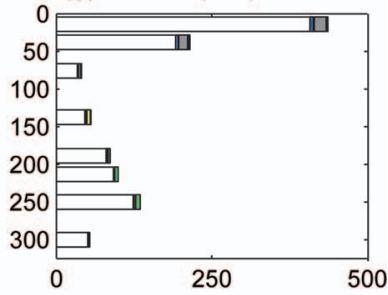

Numerical Abundance $\left(\# / \mathrm{m}^{3}\right)$ (DECEMBER 1999)

FIG. 6. Numerical abundance as a function of depth determined from the quantitative analysis of the MOCNESS net tows.

of the actual pneumatophore is filled with gas, or the extent to which the process of raising them to the surface from the depth at which they were captured and preserving them for later analysis has altered the shape. Based on length $(L)$ and width $(W)$ measurements of a sub-sample of the adult pneumatophores, it was determined that $W(\mathrm{~mm})=0.256 L(\mathrm{~mm})$ +0.085 . In this study, the pneumatophore radius is given by the equivalent spherical radius of a sphere of the same volume as a prolate ellipsoid with major and minor axes given by the measured length and width, $a=\left(L W^{2}\right)^{1 / 3} / 2$.

\section{Biological observations: Video images}

Due to the vast number of VPR images collected ( $\sim 5$ million per day) only the images for one full upward and downward tow in Jordan Basin on 6 December 1999 have been fully analyzed for all taxonomic categories and sizes. This location was chosen as it immediately followed profiles by the MOCNESS and CTD systems. At this loca-

\section{BIOMASS}

(a) MOC2 (WB): NIGHT
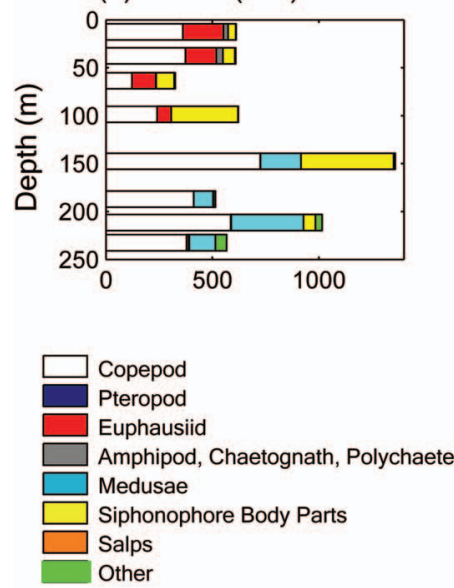

(b) MOC5 (JB): NIGHT

(c) MOC6 (GB): NIGHT

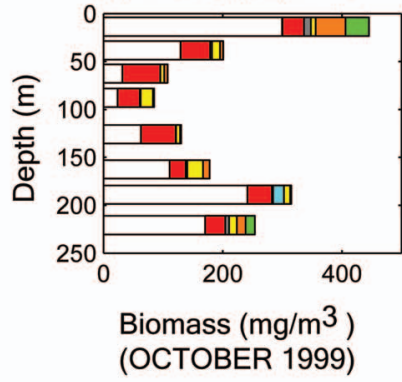

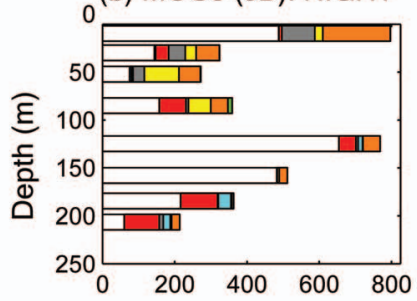

(d) MOC2 (WB):NIGHT

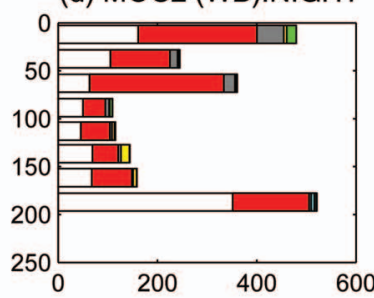

(e) MOC4 (JB): DAY

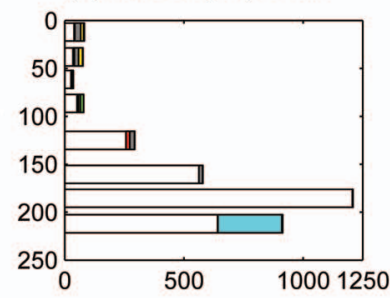

(f) MOC5 (JB): NIGHT

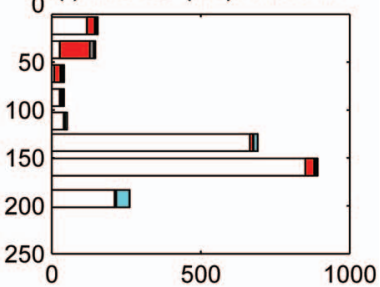

(g) MOC6 (GB): NIGHT

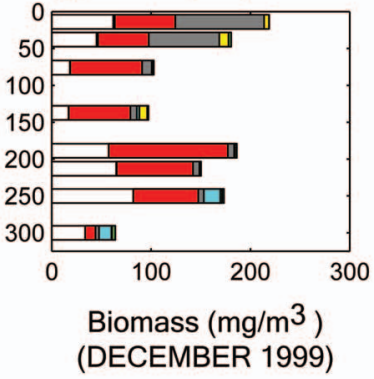

FIG. 7. Biomass as a function of depth determined from the quantitative analysis of the MOCNESS net tows.

tion, the biomass generally increased with depth and copepods made up the majority of the biomass at all depths. As a result of the small sampling volume of the VPR, the biomass and abundance only agree with the MOCNESS for small, abundant zooplankton, namely copepods. For all other zooplankton, the VPR estimates of abundance were significantly lower than the corresponding MOCNESS estimates. Previous studies have shown better agreement between VPR and MOCNESS estimates of pteropod abundance (Benfield et al., 1996), but that success was not reproduced here, possibly due to lower pteropod abundance in this study or the inherent patchiness in the distribution.

\section{DETERMINING DOMINANT SCATTERERS}

In this section, predicted dominant biological scatterers (scatterers that make up more than $50 \%$ of the total predicted scattering) are identified based on the composition and size of zooplankton in all the available MOCNESS net tows 


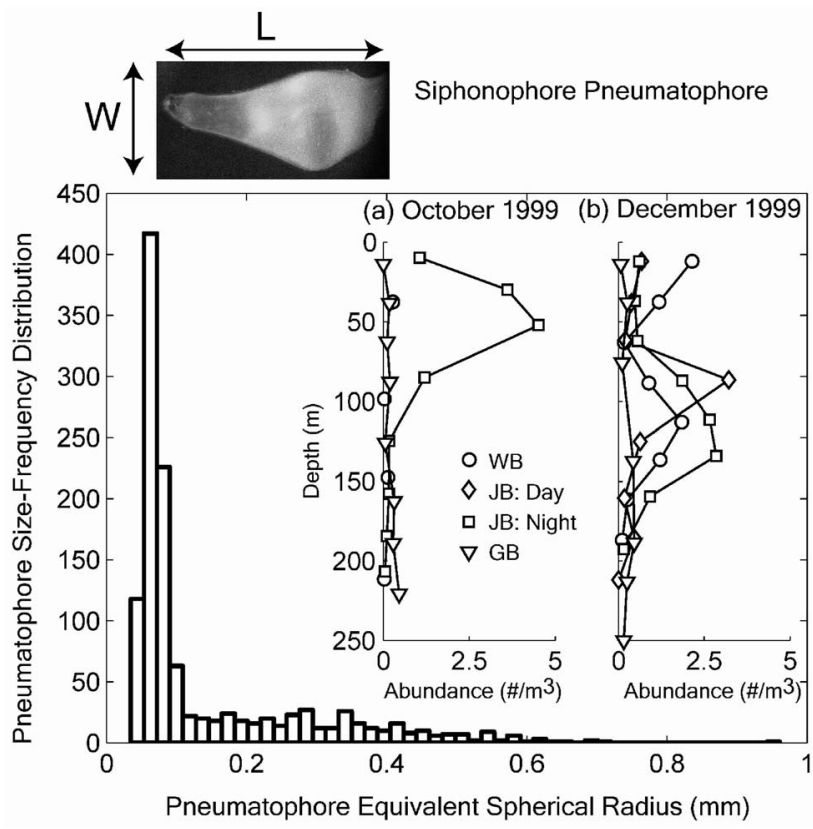

FIG. 8. Pneumatophore size-frequency distribution for all the pneumatophores observed in the deep basins of the GoM during October and December, 1999. A total of 1417 pneumatophores were measured, 121 in October and 1076 in December. The distribution is strongly peaked at a radius of $0.075 \mathrm{~mm}$, corresponding to a resonance frequency of $45 \mathrm{kHz}$ at the surface and $143 \mathrm{kHz}$ at $100 \mathrm{~m}$, approximately spanning the three lowest BIOMAPER-II frequencies. Inset: Numerical abundance of pneumatophores as a function of depth (a) in October 1999 and (b) in December 1999. The pneumatophore abundance is generally largest at the seasonal thermocline, which was deeper in December than October. The size distribution of pneumatophores did not change significantly from October to December, though the pneumatophore abundance was lower in October than in December. The image shows a pneumatophore collected by the MOCNESS.

(Figs. 9(a)-9(d)) and compared to the measured multifrequency backscattering data collected at the same time and location with BIOMAPER-II towed at the surface (Figs. 10-12). The predicted dominant biological scatterers are also identified based on the composition and size of zooplankton from video images at a select location. In addition, an upperbound contribution to volume backscattering from turbulent microstructure is calculated based on the CTD data. Scattering predictions are performed over the frequency range from $10 \mathrm{kHz}$ to $2 \mathrm{MHz}$, for comparison with the four BIOMAPER-II frequencies within that range. At locations where a single dominant scatterer could be identified, simple inversions for size and/or abundance are performed. These results are presented in this section.

\section{A. Determining dominant scatterers: Turbulent microstructure}

The predictions of scattering from turbulent microstructure based on the CTD data reveal that at most depths and locations the predicted scattering generally decreases with frequency by approximately $10-20 \mathrm{~dB}$ over the range of BIOMAPER-II frequencies. Though the magnitude of the change varied depending on the exact temperature and salinity gradients measured by the CTD (which vary with depth) and on the value of $\varepsilon$ used to make the predictions, this decrease was predicted across the frequency range of interest at most locations, depths, and values of $\varepsilon$ (Fig. 13).

Internal waves are the most likely cause for elevated values of $\varepsilon$. In an earlier study, multi-frequency acoustic observations of an internal wave in Wilkinson Basin in October 1997 (Warren et al., 2003) suggested that the observed acoustic scattering spectrum in areas of strong temperature gradients and elevated values of $\varepsilon$ are not consistent with scattering from zooplankton, showing a generally decreasing trend of volume backscattering with increasing frequency. Scattering from non-gas-bearing zooplankton of the sizes typically observed in the GoM tends to show a generally increasing trend with increasing frequency over the range of frequencies relevant to this study. A similar analysis was performed at the locations of the two internal waves that were observed in the current study (one in Jordan Basin and one in Georges Basin in December 1999), and at other select locations, including at the locations of the MOCNESS tows (Fig. 11). Generally positive slopes were observed, which is consistent with scattering from zooplankton and not microstructure. It is concluded that scattering from microstructure was not a large contributor to volume scattering during the October and December 1999 surveys, and this contribution is not included in the forthcoming analyses.

\section{B. Determining dominant biological scatterers: Nets}

The total predicted scattering of biological origin at $43 \mathrm{kHz}$ was strongly dominated by pneumatophores at most depths and locations (Fig. 9(a)). At $120 \mathrm{kHz}$, pneumatophores were still the dominant scatterers (Fig. 9(b)), but the relative contribution to scattering from siphonophore body parts had increased. At some locations where copepods were very abundant and made up most of the biomass, the contribution to the total predicted scattering from copepods became apparent at $120 \mathrm{kHz}$, though it was still small. At $200 \mathrm{kHz}$, the contribution to total scattering from pneumatophores was still significant, though only at certain locations and depths, and the contribution to total scattering from copepods dominated at some locations (Fig. 9(c)). At $420 \mathrm{kHz}$, the overall dominant predicted scatterers were copepods (Fig. 9(d)), though there were select locations where the contribution from pneumatophores was still significant, and relatively important contributions were evident from elastic-shelled pteropods in the near-surface nets. In general, the relative contribution to total predicted scattering from pneumatophores decreased with increasing frequency, while the contribution from fluid-like and elastic-shelled zooplankton increased. Though there was a significant contribution to biomass from euphausiids at some locations, their relative contribution to scattering was small at all frequencies, as the frequencies at which they would normally dominate were instead dominated by pneumatophores.

Comparison between the observed and predicted volume backscattering based on the MOCNESS tows illustrates that there is a general trend of under predicting the observed scattering (Fig. 12), except at $43 \mathrm{kHz}$. In fact, the predicted scattering was approximately $10 \mathrm{~dB}$ lower than the observed scattering if the pneumatophores were not included, and the 
(a) Relative contribution to backscattering at $43 \mathrm{kHz}$
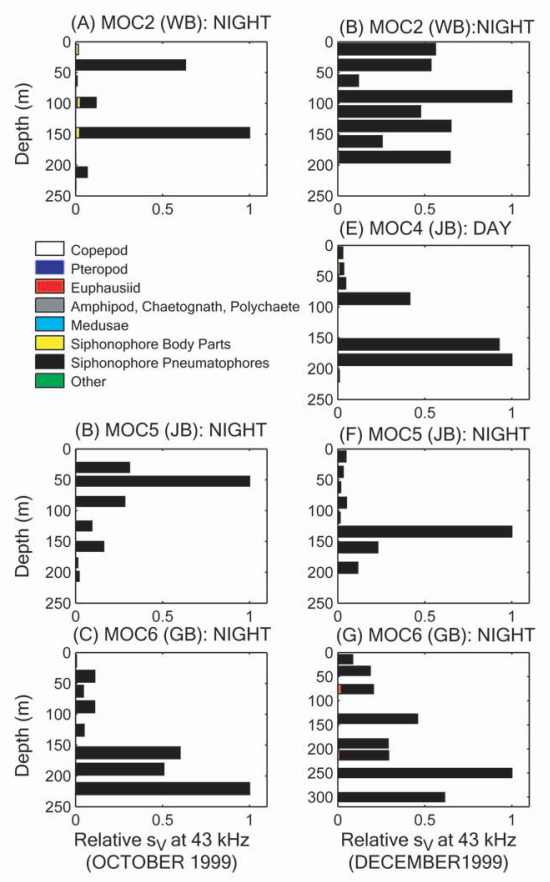

(C) Relative contribution to backscattering at $200 \mathrm{kHz}$
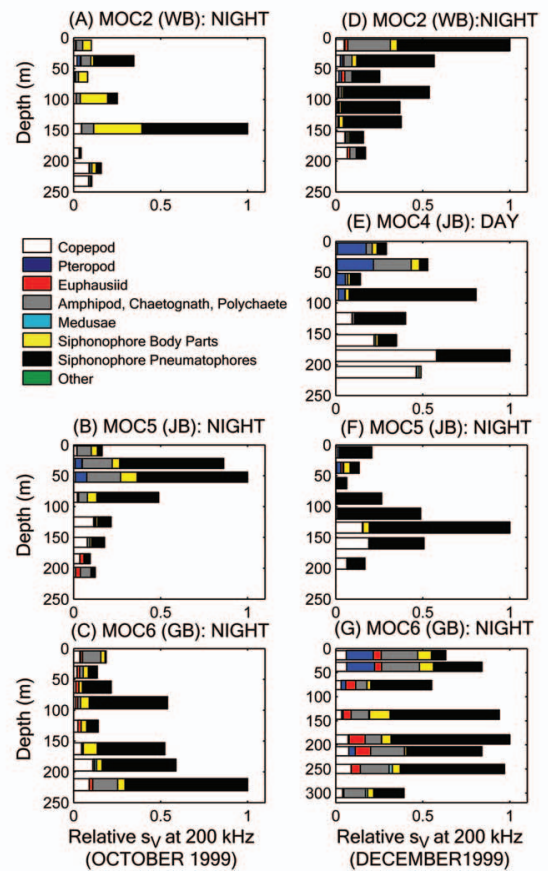

(b) Relative contribution to backscattering at $120 \mathrm{kHz}$
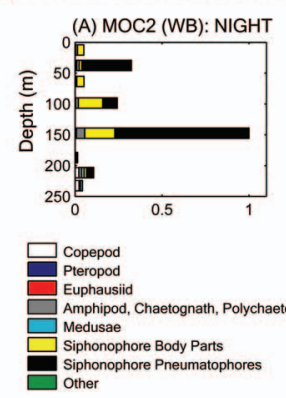

Other
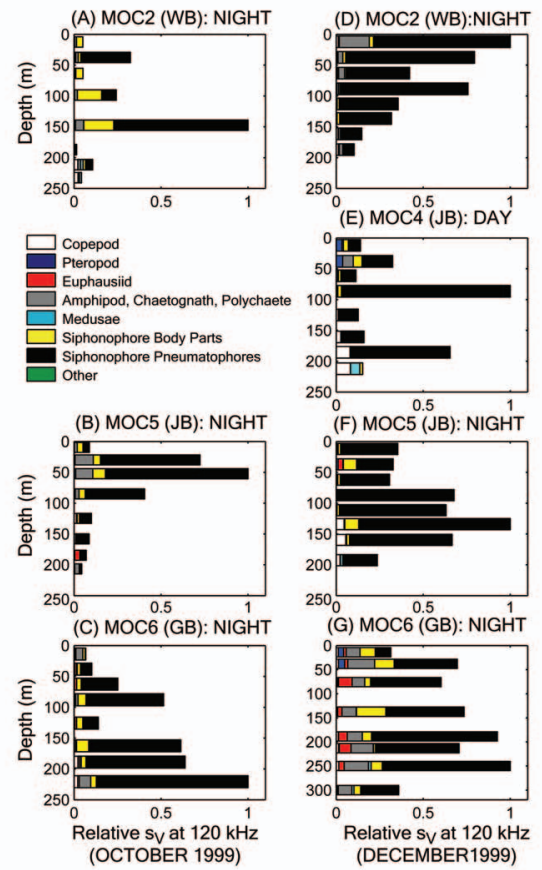

(d) Relative contribution to backscattering at $420 \mathrm{kHz}$
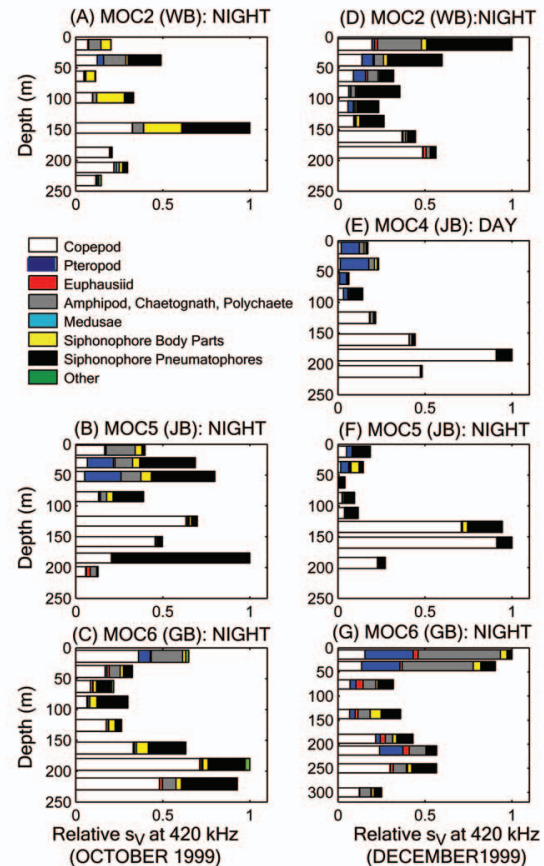

FIG. 9. Predicted dominant biological scatterers at a) $43 \mathrm{kHz}$, b) $120 \mathrm{kHz}$, c) $200 \mathrm{kHz}$, and d) $420 \mathrm{kHz}$ for all MOCNESS tows. These predictions are based on pteropod model 1. Predictions based on pteropod models 2 and 3 showed qualitatively similar results.

difference was relatively independent of location, depth, or frequency. Predicted volume backscattering for both the day and night tows appeared to under predict the observed scattering by about the same amount (results not shown). Once the pneumatophores were included in the predictions the scattering levels were in closer agreement, though the general trend of under prediction remained.

\section{Scattering dominated by fluid-like zooplankton}

Fluid-like zooplankton, and copepods in particular, dominated the total predicted volume backscattering at
$420 \mathrm{kHz}$ at most depths except near the surface where elastic-shelled pteropods were also important. At $420 \mathrm{kHz}$, the general shape of the depth dependence of the total predicted volume backscattering (Fig. 9(d)) closely resembled the corresponding shape of the measured biomass (Fig. 7). This was particularly clear during the daytime net tow (MOCNESS 4) in Jordan Basin in December 1999 at depths below $150 \mathrm{~m}$ (nets 1-3), where copepods made up a very large fraction of the biomass and contributed over $90 \%$ of the total predicted scattering. A simple single-frequency calculation of copepod abundance has been performed at this loca- 
$120 \mathrm{kHz} \mathrm{S}_{\mathrm{V}}$ and MOCNESS TRACKS

(a) MOC2 (WB): NIGHT

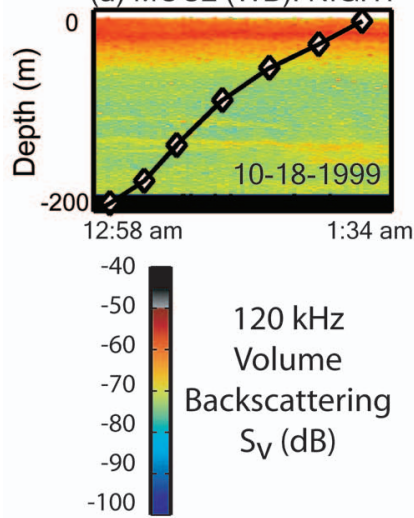

(b) MOC5 (JB): NIGHT

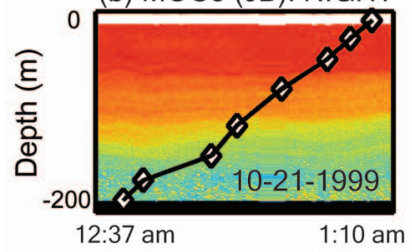

(c) MOC6 (GB): NIGHT

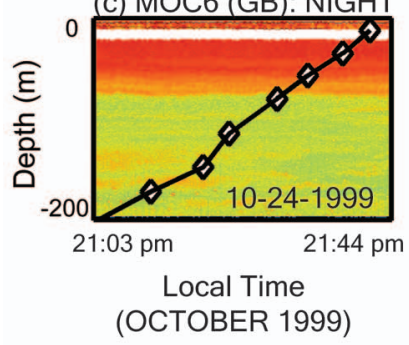

(d) MOC2 (WB):NIGHT

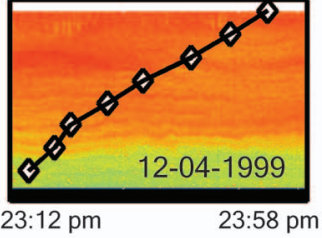

(e) MOC4 (JB): DAY

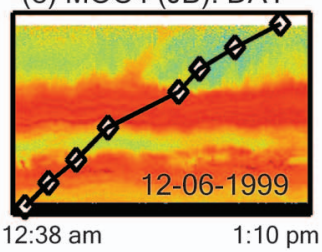

(f) MOC5 (JB): NIGHT

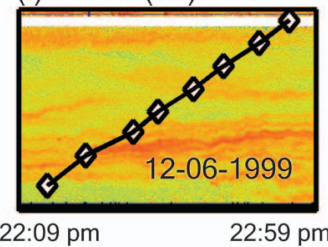

(g) MOC6 (GB): NIGHT

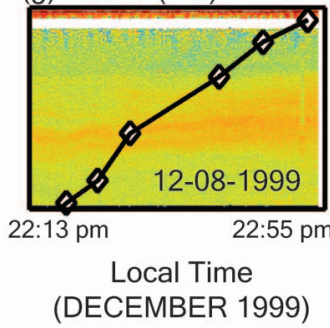

FIG. 10. Volume backscattering at $120 \mathrm{kHz}$ as a function of depth at the locations of each of the seven MOCNESS tows. BIOMAPER-II was towed at the surface $(<25 \mathrm{~m}$ depth) during all the MOCNESS tows. The black lines show the trajectory of the MOCNESS system, with the diamonds indicating the mid depths between the opening and closings of the nets.

tion, based on the measured mean volume backscattering and the mean copepod size measured in the nets. As BIOMAPER-II was towed at the surface during the deployment of the MOCNESS system, and the range on the $420 \mathrm{kHz}$ transducers was $100 \mathrm{~m}$, there were no acoustic data at $420 \mathrm{kHz}$ collected simultaneously with the MOCNESS data below $100 \mathrm{~m}$. As a result, the mean $420 \mathrm{kHz}$ volume backscattering at the location of the first tow-yo directly after the MOCNESS was used. This calculation has been performed for nets $2(175-200 \mathrm{~m})$ and $3(150-175)$, with mean $420 \mathrm{kHz} S_{v}$ values of -68.7 and $-68.5 \mathrm{~dB}$, respectively. The mean copepod lengths in these depth ranges $(2.37 \mathrm{~mm}$ in net 2 and $2.22 \mathrm{~mm}$ in net 3) give TS values of -94.8 and $-95.8 \mathrm{~dB}$, respectively. The copepod abundance is given by $s_{V} / \sigma_{\mathrm{bs}}=10^{\left(S_{V}-T S\right) / 10}$ resulting in inferred abundances of $410 / \mathrm{m}^{3}$ and $540 / \mathrm{m}^{3}$ for nets 2 and 3 , correspondingly, compared to the measured abundances of $1290 / \mathrm{m}^{3}$ and $715 / \mathrm{m}^{3}$.

\section{Scattering dominated by elastic-shelled zooplankton}

The contribution from elastic-shelled pteropods to the total predicted scattering was most important at shallow

MEAN S $\mathrm{V}_{\mathrm{V}}$ DURING MOCNESS TOWS

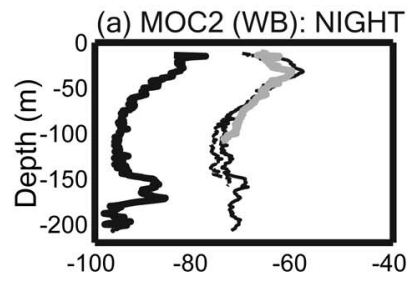

(d) MOC2 (WB):NIGHT

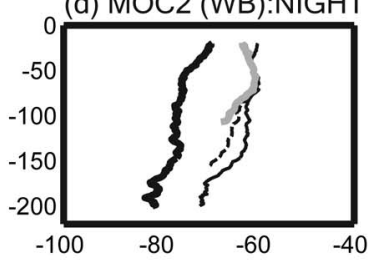

(e) MOC4 (JB): DAY
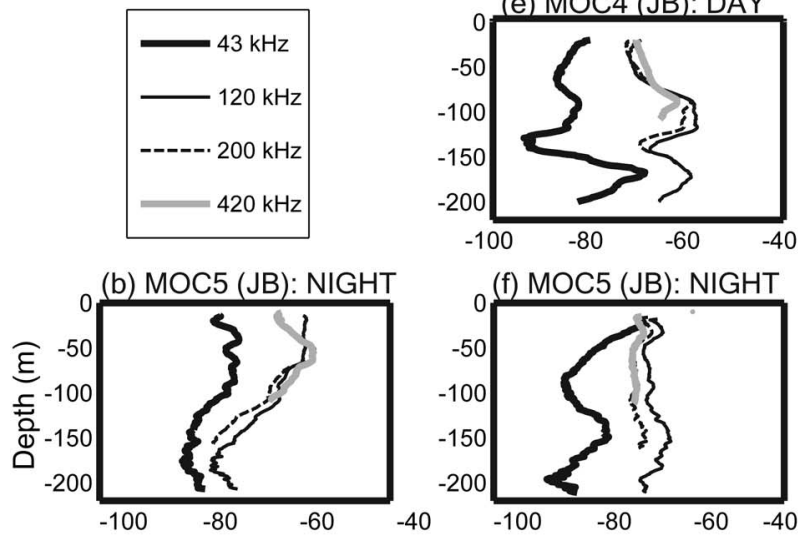

(c) MOC6 (GB): NIGHT

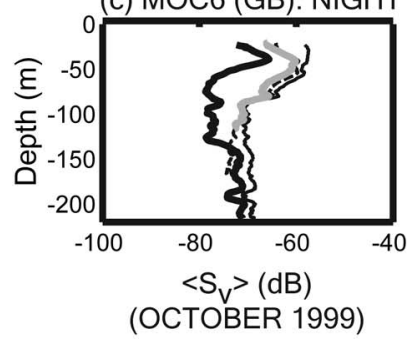

(g) MOC6 (GB): NIGHT

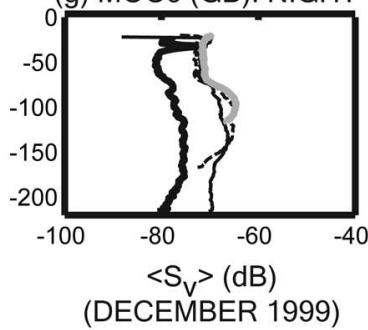

(DECEMBER 1999)

FIG. 11. Mean volume backscattering at all four BIOMAPER-II frequencies as a function of depth at the locations of each of the seven analyzed MOCNESS tows (Fig. 10). BIOMAPER-II was towed at the surface $(<25 \mathrm{~m}$ depth) during the MOCNESS tows.

depths and at high frequencies, namely 200 and $420 \mathrm{kHz}$ (Figs. 9(c) and 9(d)). The predicted contribution to scattering from pteropods has been made using the three models outlined in Sec. II D. Model 3 is exploratory in nature and was only applied to three MOCNESS tows (MOCNESS 4-6, December 1999) as the predictions based on this model are more computationally intensive. This exploratory model was attempted since, unlike the high-pass models, it does not monotonically increase with frequency and may reproduce the nonmonotonic scattering behavior observed at some locations more successfully.

The predicted scattering from pteropods never dominated (i.e., was not $>50 \%$ of the total predicted scattering) at all frequencies (Table IV). However, it did dominate at some frequencies, reaching a maximum of $70 \%$ of the total predicted scattering (based on model 1) at $420 \mathrm{kHz}$ in the 25-50 m depth bin (net 7) of the daytime MOCNESS tow (MOC 4) in Jordan Basin in December 1999 (Fig. 14). At this location and depth, the total predicted scattering based on all biological scatterers reproduced the measured scattering reasonably well at all frequencies. As expected, the contribution to scattering from pteropods increased with increasing frequency: The predicted scattering based on the 


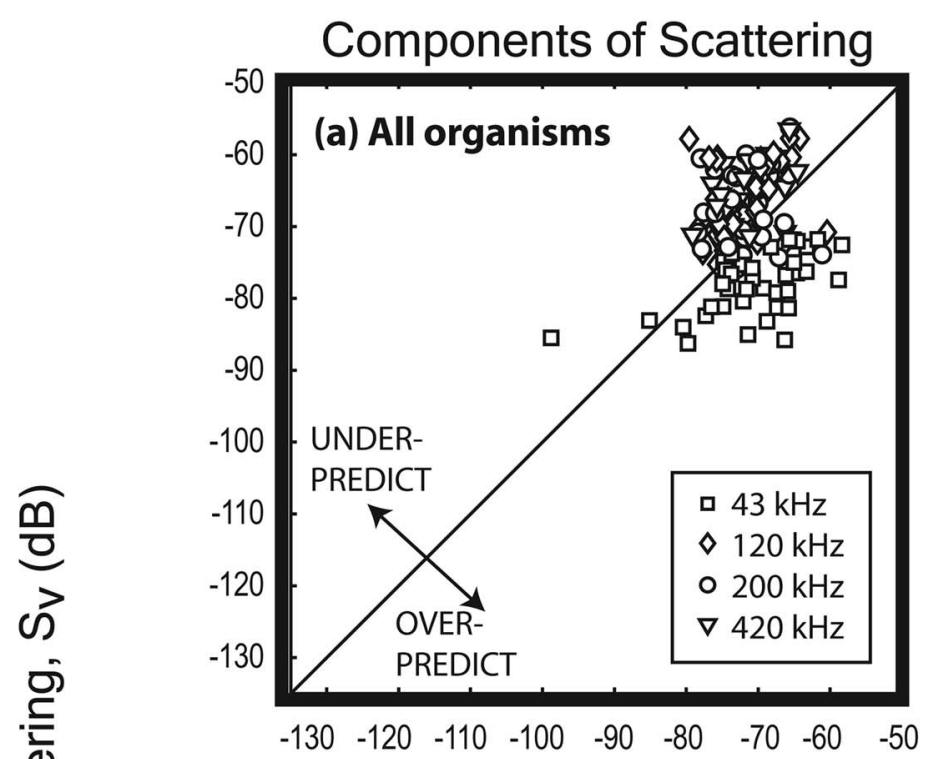

(b) Fluid-like organisms

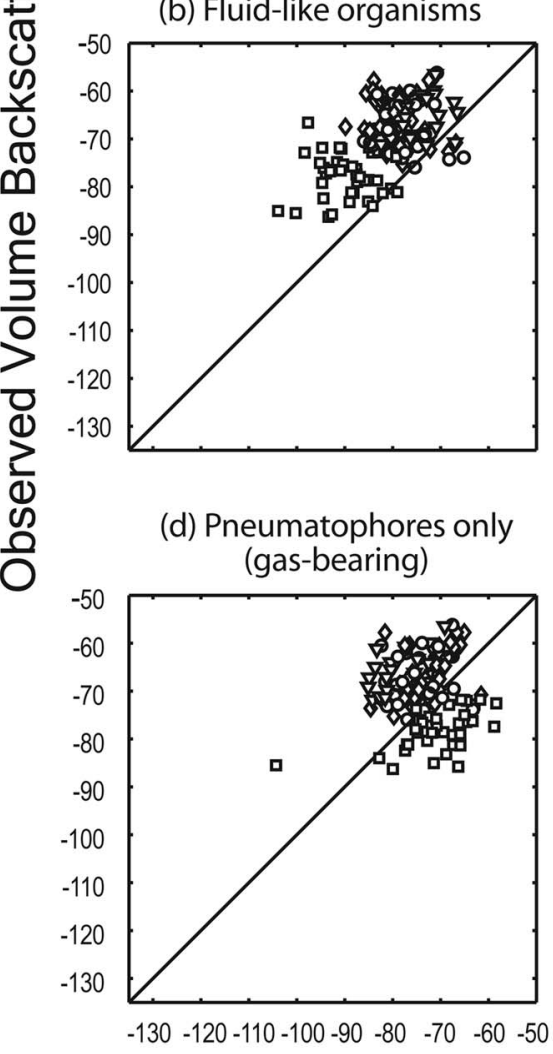

(c) Copepods only (fluid-like)

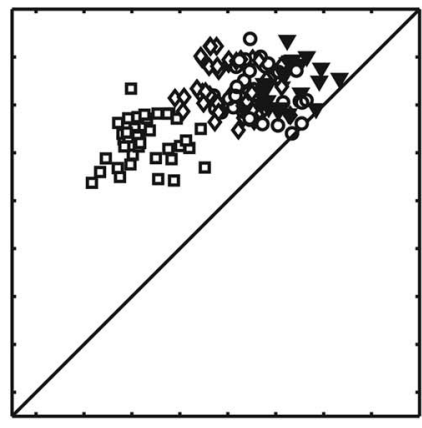

(e) Pteropods only (elastic-shelled)

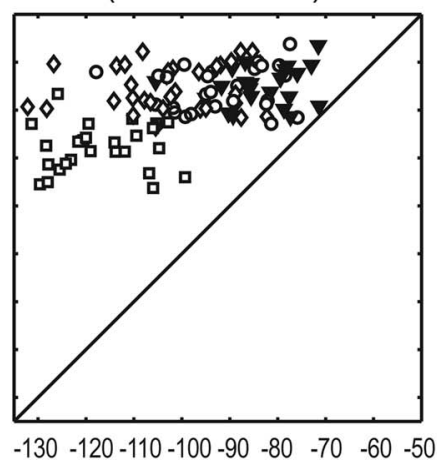

FIG. 12. Observed versus predicted volume backscattering at all frequencies for all MOCNESS tows. (a) All zooplankton, (b) fluid-like zooplankton only, (c) copepods (fluid-like) only, (d) pneumatophores (gasbearing siphonophores) only, and (e) pteropods (elasticshelled) only. The $43 \mathrm{kHz}$ data from MOC 2 in October 1999 have been discarded due to suspect noise profiles. The black lines show the one-to-one linear relationship that would be obtained if the predicted and observed scattering agreed perfectly. The solid black triangles in (c) and (d) highlight the $420 \mathrm{kHz}$ data.

\section{Predicted Volume Backscattering, $\mathrm{S}_{\mathrm{V}}(\mathrm{dB})$}

pteropods alone was significantly smaller than the observed backscattering at 43 and $120 \mathrm{kHz}$, regardless of model, but the predicted scattering from pteropods based on both highpass models (models 1 and 2) was in relatively good agreement with the measured scattering at 200 and $420 \mathrm{kHz}$. Pteropod model 3 significantly over-predicted the scattering at 200 and $420 \mathrm{kHz}$. As the predicted scattering from pteropods dominated at $420 \mathrm{kHz}$ at this location and depth, based on all models, a single-frequency inference of pteropod abundance was performed, assuming a known pteropod size (mean size in MOC4 net 7). The predictions compared favorably to the measured MOCNESS pteropod abundance (Table V).

\section{Scattering dominated by gas-bearing zooplankton}

Siphonophore pneumatophores were important contributors to volume scattering throughout the deep basins of the GoM. Pneumatophores were particularly abundant at the depth of the seasonal thermocline, where a strong scattering layer was often observed with volume scattering levels 


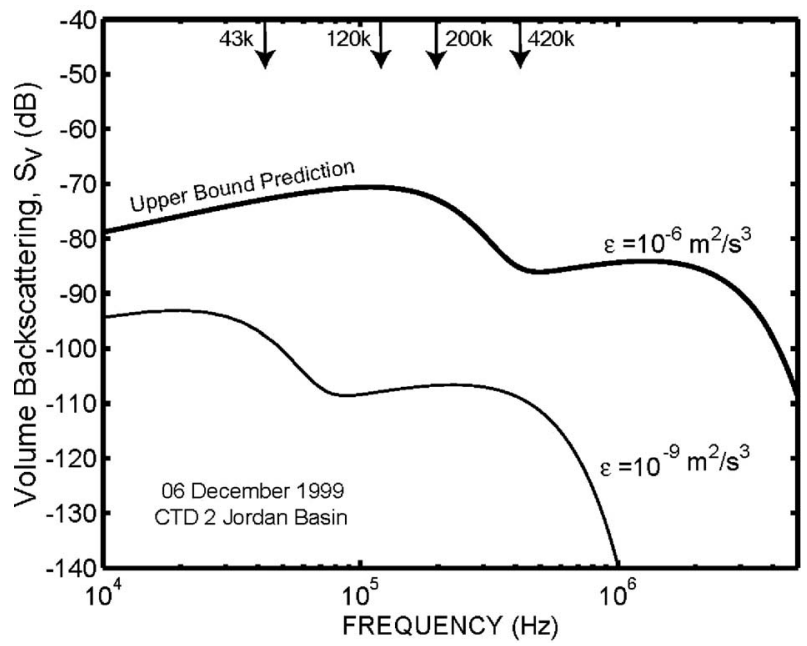

FIG. 13. Predicted volume backscattering for turbulent microstructure as a function of frequency based on parameters estimated from CTD 2 on 6 December 1999. These predictions are based on an assumed value of $\varepsilon$ $=10^{-6} \mathrm{~m}^{2} / \mathrm{s}^{3}$ (thick line) and on the maximum temperature and salinity gradients observed at any depth, giving an upper bound prediction. Actual values are expected to fall well below this prediction. Predictions based on $\varepsilon=10^{-9} \mathrm{~m}^{2} / \mathrm{s}^{3}$ (thin line) are shown to indicate that the shapes of the curves are generally similar, independent of the exact value of $\varepsilon$ The scattering generally decreases across the BIOMAPER-II frequency range.

reaching a maximum at $120 \mathrm{kHz}$. A particularly strong scattering layer at the seasonal thermocline was observed in Jordan Basin on 6 December 1999. MOCNESS 4 and CTD 2 were performed in close succession at this location, with BIOMAPER-II collecting acoustic data while at the surface (Fig. 15). A second deeper scattering layer was also observed.

Though relatively strong temperature gradients were observed at the depths corresponding to the two scattering layers (Fig. 16(a)), the measured scattering spectra for the layers are not consistent with the predicted scattering from turbulent microstructure. The total biomass and numerical abundance of zooplankton based on the MOCNESS samples reached a minimum at the location of the scattering layer at the seasonal thermocline and a maximum at the location of the deeper scattering layer (Fig. 16(b)). However, there was an elevated numerical abundance of siphonophore pneumatophores in the scattering layer at the seasonal thermocline (Fig. 16(b)), though the numerical abundance of pneumatophores was small $\left(<4 / \mathrm{m}^{3}\right)$ compared to the total abundance of zooplankton at this depth $\left(186 / \mathrm{m}^{3}\right)$. This suggests that two different mechanisms (both of biological origin) are giving rise to the scattering layers: the strong and pervasive scattering layer at the seasonal thermocline due predominantly to pneumatophores and the deeper scattering

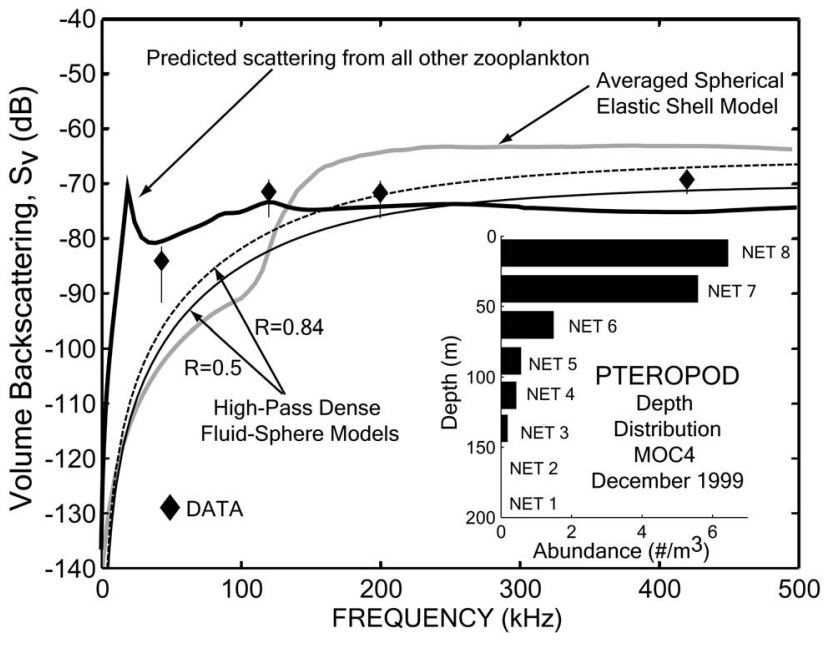

FIG. 14. Predicted volume backscattering in Jordan Basin, GoM, on 6 December 1999 based on the measured distribution of pteropods in MOCNESS 4 Net $7(25-50 \mathrm{~m})$. Predictions are based on three models: the high-pass dense fluid-sphere model with reflection coefficients of $R=0.5$ (thin solid line) and $R=0.84$ (thin dashed line), and the averaged modal series solution for a spherical aragonite shell (thick gray line). The mean measured $S_{V}$ values for this depth range are shown by the solid diamonds. The error bars indicate the standard deviation of the mean measured $S_{V}$ values. The total predicted $S_{V}$ based on all the remaining zooplankton for this depth stratum is shown (thick black line). The inset shows the vertical distribution of pteropod abundance at this location.

layer due to an elevated abundance of other zooplankton. Though there are differences between the predicted and observed scattering at this location, the predicted scattering if the pneumatophores are not included does not even qualitatively reproduce the observed scattering trends, and underpredicts the scattering at $120 \mathrm{kHz}$ by almost $35 \mathrm{~dB}$ (results not shown). Elevated scattering at the seasonal thermocline has been observed at multiple acoustic frequencies previously (e.g., Holliday and Pieper, 1980), though no satisfactory explanation of its origin has been suggested.

As the predicted scattering in the layer at the seasonal thermocline is dominated $(>50 \%$ of the total predicted scattering) by pneumatophores at all frequencies, a simple least squares inversion was performed in which the scattering was assumed to arise solely from pneumatophores of a single size, and the radius and abundance were varied to give the best possible fit to the measured $S_{v}$ data (Fig. 17). The pneumatophore diameter $(0.15 \mathrm{~mm})$ obtained by this simple inversion was virtually identical to the median pneumatophore diameter measured by the MOCNESS in that depth stratum. However, the inferred abundance was significantly higher $\left(216 / \mathrm{m}^{3}\right)$ than the measured abundance $\left(3.2 / \mathrm{m}^{3}\right)$. These kinds of simple inversions have been performed previously

TABLE IV. Number of MOCNESS nets in which the contribution from copepods, pteropods, and siphonophores to the total predicted volume backscattering of biological origin was larger than $50 \%$. The quantities in the parentheses represent these numbers as a percentage of the total number of nets: The number of MOCNESS tows analyzed in this study was 7, and each tow had eight nets, thus the total number of nets analyzed was 56.

\begin{tabular}{lcccc}
\hline \hline Organism & $43 \mathrm{kHz}$ & $120 \mathrm{kHz}$ & $200 \mathrm{kHz}$ & $420 \mathrm{kHz}$ \\
\hline Copepods (fluid-like) & $0(0 \%)$ & $2(3.6 \%)$ & $7(12.5 \%)$ & $22(39.3 \%)$ \\
Pteropods (elastic-shell) & $0(0 \%)$ & $0(0 \%)$ & $1(1.8 \%)$ & $3(5.4 \%)$ \\
Siphonophore Pneumatophores (gas-bearing) & $49(85.7 \%)$ & $43(76.7 \%)$ & $30(53.6 \%)$ & $9(16.1 \%)$ \\
\hline \hline
\end{tabular}


TABLE V. Acoustically inferred zooplankton size and/or abundance for different zooplankton taxa that dominate the scattering at one or more frequencies. If the scattering was dominated at all frequencies by a single type of scatterer, a four-frequency inversion for size (assuming a single size) and numerical abundance was performed. Otherwise, a single-frequency inversion for numerical abundance was performed assuming a known size and based on the frequency at which the organisms most dominated the total predicted scattering. The measured organism size corresponds to the mean size in the depth bin indicated, estimated by the corresponding sampling method. For copepods and eupahusiids size corresponds to length, and for pteropods and pneumatophores size corresponds to diameter. The frequencies that were used to perform the inversions are highlighted. Where applicable, the depth range of the measurements is noted.

\begin{tabular}{|c|c|c|c|c|c|c|c|c|}
\hline Organism & $\begin{array}{l}\text { Fraction } \\
\text { of total } \\
\text { biomass }\end{array}$ & $\begin{array}{c}\text { Fraction } \\
\text { of total } \\
\text { numerical } \\
\text { abundance }\end{array}$ & $\begin{array}{c}\text { Fraction of } \\
\text { contribution to } \\
\text { scattering at each } \\
\text { frequency }\end{array}$ & $\begin{array}{l}\text { Measured } \\
\text { Size } \\
(\mathrm{mm})\end{array}$ & $\begin{array}{l}\text { Acoustically } \\
\text { inferred } \\
\text { size } \\
(\mathrm{mm})\end{array}$ & $\begin{array}{c}\text { Measured } \\
\text { abundance } \\
\left(\# / \mathrm{m}^{3}\right)\end{array}$ & $\begin{array}{c}\text { Acoustically inferred } \\
\text { abundance }\left(\# / \mathrm{m}^{3}\right)\end{array}$ & $\begin{array}{l}\text { Sampling technique, } \\
\text { location, } \\
\text { date, } \\
\text { depth }\end{array}$ \\
\hline $\begin{array}{l}\text { Copepods }^{\mathrm{a}} \\
\text { (Fluid-like) }\end{array}$ & $99.8 \%$ & $98.9 \%$ & $\begin{array}{l}0.1 \%(43 \mathrm{kHz}) \\
12 \%(120 \mathrm{kHz}) \\
58 \%(200 \mathrm{kHz}) \\
\mathbf{9 1 \%}(\mathbf{4 2 0} \mathbf{~ k H z})\end{array}$ & 2.37 & NA & 1290 & 410 & $\begin{array}{c}\text { MOCNESS } \\
\text { Jordan Basin, GoM } \\
\text { December 1999 } \\
\text { MOC 4, Net 2: } 175-200 \mathrm{~m}\end{array}$ \\
\hline $\begin{array}{l}\text { Copepods }^{\mathrm{a}} \\
\text { (Fluid-like) }\end{array}$ & $97.2 \%$ & $98.8 \%$ & $\begin{array}{l}0.03 \%(43 \mathrm{kHz}) \\
17 \%(120 \mathrm{kHz}) \\
63 \%(200 \mathrm{kHz}) \\
\mathbf{9 2 \%}(\mathbf{4 2 0} \mathbf{~ k H z})\end{array}$ & 2.22 & NA & 715 & 540 & $\begin{array}{c}\text { MOCNESS } \\
\text { Jordan Basin, GoM } \\
\text { December 1999 } \\
\text { MOC 4, Net 3: 150-175 m }\end{array}$ \\
\hline $\begin{array}{l}\text { Copepods } \\
\text { (Fluid-like) }\end{array}$ & See note ${ }^{c}$ & See note ${ }^{c}$ & See note & 2.45 & NA & 930 & $355^{\mathrm{d}}$ & $\begin{array}{c}\text { VPR } \\
\text { Jordan Basin, GoM } \\
\text { December } 1999 \\
175-200 \mathrm{~m}\end{array}$ \\
\hline $\begin{array}{l}\text { Copepods }^{\mathrm{b}} \\
\text { (Fluid-like) } \\
\text { (Video: VPR) }\end{array}$ & See note ${ }^{c}$ & See note ${ }^{c}$ & See note ${ }^{c}$ & 2.46 & NA & 645 & $370^{\mathrm{d}}$ & $\begin{array}{c}\text { VPR } \\
\text { Jordan Basin, GoM } \\
\text { December } 1999 \\
150-175 \mathrm{~m}\end{array}$ \\
\hline $\begin{array}{l}\text { Pteropods }^{\mathrm{a}} \\
\text { (Elastic shell) }^{\text {Elic }}\end{array}$ & $5.9 \%$ & $2.0 \%$ & $\begin{array}{c}1 \%(43 \mathrm{kHz}) \\
11 \%(120 \mathrm{kHz}) \\
40 \%(200 \mathrm{kHz}) \\
\mathbf{7 0 \%}(\mathbf{4 2 0} \mathbf{~ k H z})\end{array}$ & 0.996 & NA & 5.57 & $\begin{array}{c}10.6(\text { model } 1) \\
4.3(\text { model } 2) \\
0.66(\text { model } 3)\end{array}$ & $\begin{array}{c}\text { MOCNESS } \\
\text { Jordan Basin, GoM } \\
\text { December } 1999 \\
\text { MOC 4, Net 7: } 25-50 \mathrm{~m}\end{array}$ \\
\hline $\begin{array}{l}\text { Siphonophore } \\
\text { Pneumatophores } \\
\text { (Gas-bearing) }\end{array}$ & NA & $1.7 \%$ & $\begin{array}{l}99 \%(43 \mathrm{kHz}) \\
97 \%(120 \mathrm{kHz}) \\
92 \%(200 \mathrm{kHz}) \\
65 \%(420 \mathrm{kHz})\end{array}$ & 0.15 & 0.15 & 3.2 & 216 & $\begin{array}{c}\text { MOCNESS } \\
\text { Jordan Basin, GoM } \\
\text { December 1999 } \\
\text { MOC 4, Net 5: 75-100 m }\end{array}$ \\
\hline $\begin{array}{l}\text { Euphausiids } \\
\text { (Fluid-like) }^{\mathrm{f}} \\
\text { (Warren, 2001; } \\
\text { Warren et al., 2003) }\end{array}$ & $7 \%$ & $<1 \%$ & $\begin{array}{l}50 \%(43 \mathrm{kHz}) \\
80 \%(120 \mathrm{kHz}) \\
75 \%(200 \mathrm{kHz}) \\
65 \%(420 \mathrm{kHz})\end{array}$ & 14.7 & 15 & 1 & 11 & $\begin{array}{c}\text { MOCNESS } \\
\text { Jordan Basin, GoM } \\
\text { December 1999 } \\
\text { MOC 9, Net 5: 60-80 m }\end{array}$ \\
\hline
\end{tabular}

\footnotetext{
a Abundance estimated from single-frequency $(420 \mathrm{kHz})$ inversion, assuming a known size.

${ }^{b} 1$ st VPR tow, performed shortly after MOC 4. Abundance estimated from single-frequency (420 kHz) inversion, assuming a known copepod size, as estimated from the VPR video images.

${ }^{\mathrm{c}}$ Due to the small VPR sampling volume, the total biomass and numerical abundance of zooplankton were overwhelmingly dominated by copepods. As a result, the VPR-based predictions of volume scattering were also dominated at all frequencies by copepods.

${ }^{\mathrm{d}}$ The VPR estimates of copepod length were larger than the MOCNESS (MOC 4) estimates of copepod length, potentially due to ambiguities in the orientation of the copepods in the VPR images, due to the 2-D projection of a 3-D object onto the video image plane. TS=-94.2 $\mathrm{dB}$ for a copepods of length $2.45-2.46 \mathrm{~mm}$.

${ }^{\mathrm{e}}$ Abundance and size inferred from 4-frequency inversion.

${ }^{\mathrm{f}}$ These studies involved data collected with the same multi-frequency towed instrument platform, BIOMAPER-II, in an earlier survey of Wilkinson Basin in the Gulf of Maine in October 1997. Direct biological sampling was performed using the MOCNESS to ground truth the acoustic data.
}

with some success (Warren et al., 2003; Trevorrow et al., 2005). The assumption of a single pneumatophore size is partially justified as the observed pneumatophore size distribution was peaked around a single size. Inversion of the multi-frequency data for the location of the resonance frequency (or the Rayleigh-to-geometric scattering transition) provides a relatively accurate method for determining size. In contrast, absolute scattering levels are subject to the vagaries of calibration, in addition to which there is uncertainty in the abundance measured by net tows due to issues such as avoidance and destruction of fragile individuals. Thus, these simple inversions typically predict size with greater accuracy than these inversions predict abundance.

\section{Determining dominant biological scatterers: Video images}

Volume backscattering predictions were performed based on the VPR video images collected during the first BIOMAPER-II tow in Jordan Basin on 6 December 1999 (Fig. 15). The biomass and numerical abundance of zooplankton as determined by the VPR were overwhelmingly dominated by copepods at all depths. A total of only 13 images were not copepods, divided almost equally into euphausiids, chaetognaths, ostracods, and larvaceans (all fluidlike scatterers), two elastic-shelled pteropods, and three gasbearing siphonophores. The predicted volume backscattering

Lavery et al:: Dominant scatterers in mixed zooplankton populations 


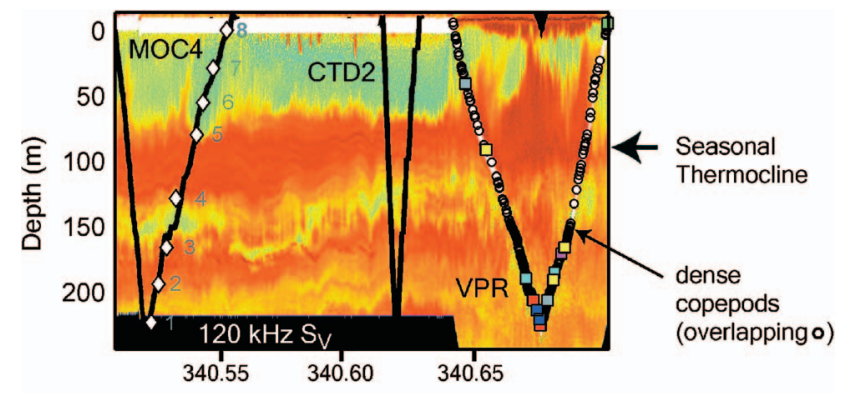

Local Time (Year Day, 1999)

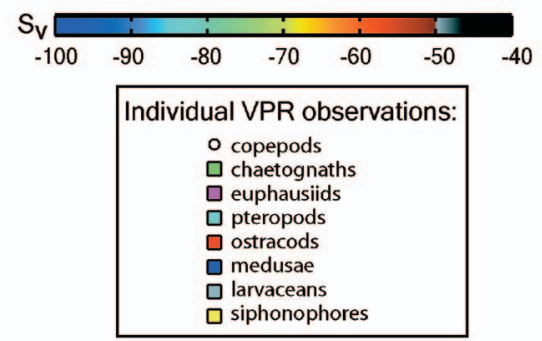

FIG. 15. Volume backscattering at $120 \mathrm{kHz}$ as a function of depth and local time in Jordan Basin, GoM, on 6 December 1999. The MOCNESS 4 and CTD 2 profiles are shown. The depths of the opening and closing of the 8 MOCNESS nets are indicated by open diamonds. The depths of all the individual VPR observations of different zooplankton taxa are marked. MOCNESS 4 was completed at 13:45 while the first BIOMAPER-II towyo was completed at 16:45 (sunset was at 15:57). The BIOMAPER-II track line is indicated in white. The time elapsed from the beginning of the MOCNESS to the end of the first towyo is approximately $4.5 \mathrm{~h}$.

from copepods (Fig. 18), based on the VPR images, is in better agreement with the observed scattering at the higher frequencies and at the deeper depths, where copepods were most abundant, though the predicted scattering at $420 \mathrm{kHz}$ based on just the copepods was a few $\mathrm{dB}$ larger than the observed scattering at the deeper depths. The predicted scattering based on the remaining taxa did not contribute significantly to scattering at most depths or frequencies. At the few depths where siphonophores were observed, there are spikes in the predicted scattering, in some cases many $\mathrm{dB}$ above the predicted backscattering from copepods, and that were not observed in the measured volume backscattering, a result that can be easily explained by the large differences in the acoustic and VPR sampling volumes. There is little evidence that any type of zooplankton observed by the VPR can account for the scattering layer observed at the seasonal thermocline, though the deeper scattering layer can be explained by an elevated abundance of copepods, consistent with the presence of elevated biomass and numerical abundance at depth caused by overwintering copepods, specifically Calanus finmarchicus.

As copepods dominated the biomass, numerical abundance, and total predicted volume backscattering at this location (based on the VPR images), it is possible to perform a simple single-frequency inference of copepod abundance based on the measured volume backscattering and VPRbased estimate of copepod length. As the predicted and measured $S_{V}$ values were in closest agreement at $420 \mathrm{kHz}$ and below $150 \mathrm{~m}$ depths, the numerical abundance of copepods was inferred acoustically at all depths in $1 \mathrm{~m}$ bins between 150 and $200 \mathrm{~m}$ based on the measured $420 \mathrm{kHz} S_{V}$ data (Fig.

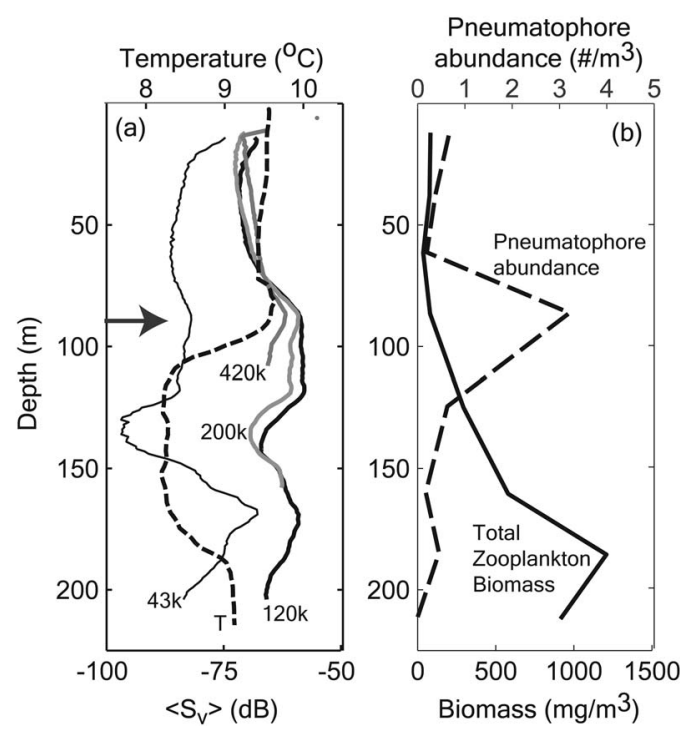

FIG. 16. (a) Mean volume backscattering as a function of depth at 43, 120, 200, and $420 \mathrm{kHz}$ in Jordan Basin, GoM, on 6 December 1999 during the deployment of MOCNESS 4. Two strong scattering layers are observable at $120 \mathrm{kHz}$ : A layer approximately $40 \mathrm{~m}$ wide centered at $105 \mathrm{~m}$, and a deeper layer, approximately $20 \mathrm{~m}$ wide, centered at $170 \mathrm{~m}$. The arrow indicates the approximate depth of the seasonal thermocline. The volume backscattering at $43 \mathrm{kHz}$ is significantly weaker than at the other frequencies. The deeper layer is not fully observed at $200 \mathrm{kHz}$, while at $420 \mathrm{kHz}$ the shallower layer is only partially observable. Superimposed on the mean $S_{V}$ values is the temperature profile obtained by the nearby CTD 2 (thick dashed line corresponding to the scale on the top axis). (b) Total zooplankton biomass estimated from MOCNESS 4 (thick line, bottom scale) and numerical abundance of pneumatophores (dashed line, top scale). It can be seen that there is a peak in the biomass at $185 \mathrm{~m}$, and a peak in the numerical abundance of pneumatophores at $85 \mathrm{~m}$, corresponding to net 5 , spanning the depth range from 75 to $100 \mathrm{~m}$.

18(d)) and TS values based on the mean copepod lengths in the $1 \mathrm{~m}$ depth bins. These $S_{V}$ values were also used in Sec. V B 1 to calculate the numerical abundance of copepods based on copepod lengths from the nearby MOCNESS data. For ease of comparison with the numerical abundance based on

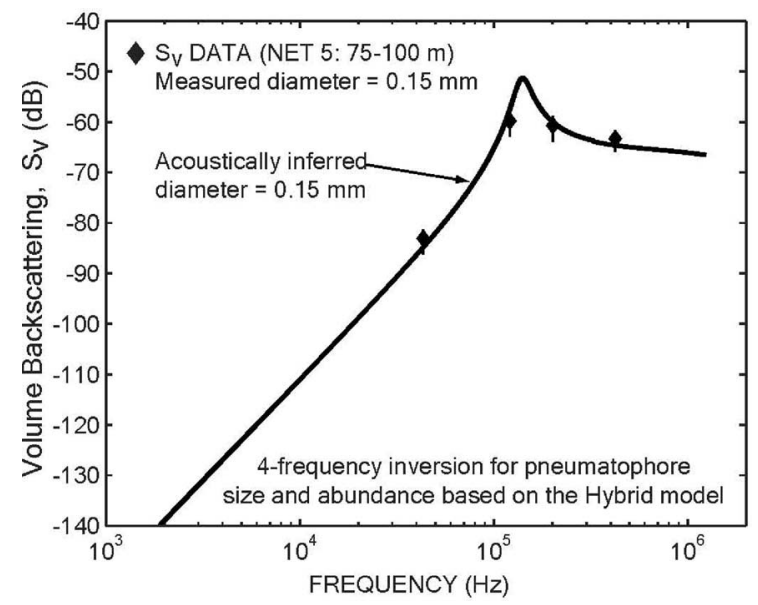

FIG. 17. Observed volume backscattering (diamonds) in Jordan Basin, GoM, on 6 December 1999 in the depth stratum spanning 75-100 m (MOC 4 net 5), and the results of a four-frequency least squares inversion (based on the hybrid model) for pneumatophore radius and abundance (solid line). This simple inversion assumes the scattering is due to pneumatophores of a single size. The error bars indicate the standard deviation of the mean measured $S_{V}$ values. 
(a) $43 \mathrm{kHz}$

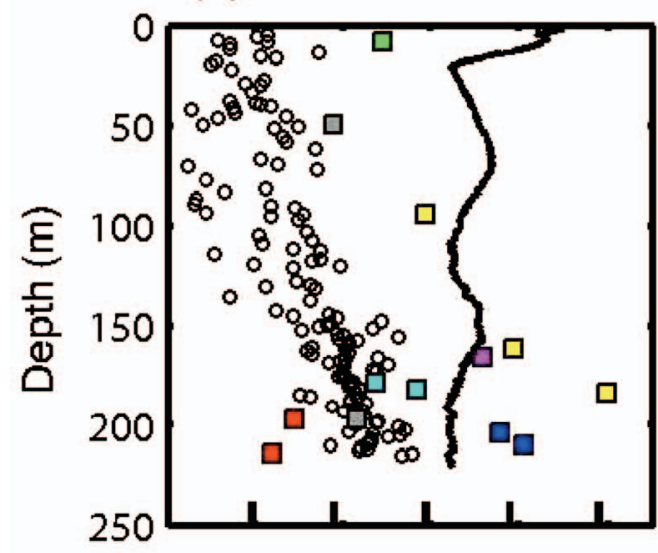

(c) $200 \mathrm{kHz}$

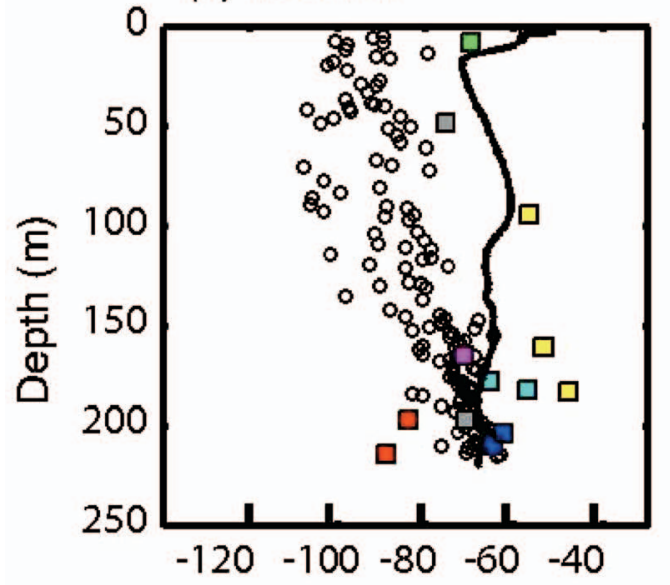

(b) $120 \mathrm{kHz}$

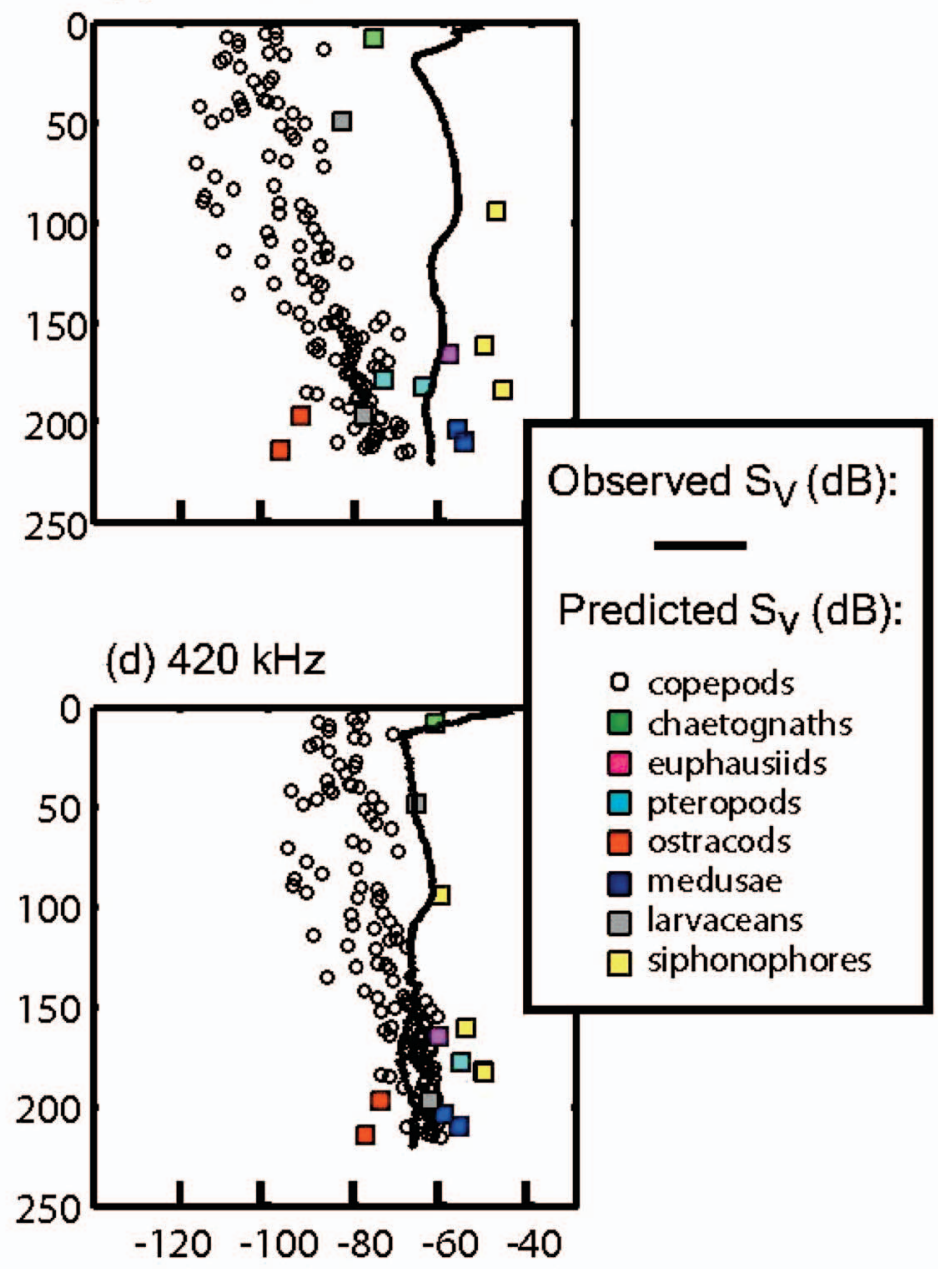

Volume Backscattering, $S_{V}(d B)$ based on VPR images

FIG. 18. Predicted volume backscattering as a function of depth based the VPR images for the first tow in Jordan Basin, GoM, on 6 December 1999 at the four BIOMAPER-II frequencies: a) $43 \mathrm{kHz}$, b) $120 \mathrm{kHz}$, c) $200 \mathrm{kHz}$, and d) $420 \mathrm{kHz}$. The solid lines correspond to the mean measured volume backscattering. The symbols correspond to the predicted volume backscattering, averaged in $1 \mathrm{~m}$ depth bins, for the different zooplankton taxa observed in the VPR images. As it was not possible to measure the pneumatophore sizes for the siphonophores observed with the VPR, the pneumatophore sizes used were based on the median pneumatophore size measured in the nearby MOCNESS samples at the corresponding depths.

the nearby MOCNESS data, the numerical abundance has been averaged into depth bins that correspond to the depths of nets 2 and 3 of the nearby MOCNESS. The acoustically inferred numerical abundance of copepods in the 175-200 $\mathrm{m}$ depth bin was $355 / \mathrm{m}^{3}$, compared to the VPRbased estimate of $930 / \mathrm{m}^{3}$, and the acoustically inferred numerical abundance of copepods in the 150-175 m depth bin was $370 / \mathrm{m}^{3}$, compared to the VPR-based estimate of $645 / \mathrm{m}^{3}$.

\section{DISCUSSION AND CONCLUSIONS}

It has been found that in the mixed zooplankton populations investigated in this study, a single type of scatterer does not often dominate the scattering at all frequencies (Tables IV and V). Instead, low abundances of strong scatterers that do not contribute significantly to overall biomass dominated the scattering over a sub-range of frequencies. For example, siphonophores with small gas-filled pneumatophores dominated the scattering at the lower frequencies, particularly at $43 \mathrm{kHz}$, at many locations and depths. Elasticshelled pteropods that also made a very small contribution to biomass were important scatterers in the near-surface waters at higher frequencies, particularly at $420 \mathrm{kHz}$. Millimetersized weakly scattering copepods were highly abundant and made up the majority of the biomass at many locations, however, their contribution to scattering was not apparent except at the highest frequencies. Most other fluid-like zooplankton, including euphausiids, never dominated the scattering at any frequency.

The accuracy of acoustic scattering models for interpreting the measured volume backscattering data is critical. The scattering model employed in this study for most fluid-like zooplankton was based on the DWBA smoothly-tapered, uniformly-bent cylinder model, an extensively tested formu- 
lation. The scattering from siphonophores with gas inclusions was described using a hybrid model that accounts for damping near the bubble resonances and used the actual distribution of measured bubble sizes. Siphonophore body parts were modeled as fluid spheres. Given the uncertainty in the elastic-shell scattering model used for pteropods, several models were used ranging from a semi empirical high-pass dense fluid-sphere model, through to an averaged exact modal series solution for an elastic shell, which has not been applied previously to pteropods. Since there were no regions in which the scattering from pteropods dominated the scattering at all frequencies based on any of these models, it was difficult to assess which scattering model was most accurate. However, at the few locations and frequencies where the scattering was dominated by pteropods, the high-pass models most accurately predicted the observed scattering. The scattering models for all types of zooplankton were challenged by the need for precise model parameters, in particular, the in situ characteristics (shape and size) of the siphonophore gas inclusions and the material properties of elastic-shelled pteropods.

In contrast to earlier studies in this region (Warren et al., 2003), there was little evidence that turbulent oceanic microstructure was a significant contributor to volume backscattering. Warren et al. were probably able to observe scattering from turbulent microstructure during the passage of an internal wave for a combination of reasons: 1) Their measurements were conducted at a time and location when the stratification was slightly stronger, 2) their measurements were performed in the far eastern part of Wilkinson Basin, a region that may also have been more susceptible to internal waves with elevated dissipation rates of turbulent kinetic energy, and 3) during their measurements, the contribution to scattering of biological origin, at least in certain portions of the internal wave, was sufficiently low that it did not mask the scattering from turbulent microstructure.

The measured scattering at most locations investigated in this study generally increased monotonically with increasing frequency, across the frequency range pertinent to this study, though the scattering at $120 \mathrm{kHz}$ was typically largest for a pervasive scattering layer observed at the seasonal thermocline, consistent with the presence of gas-bearing siphonophores, a conclusion also supported by net-based forward predictions of expected backscattering. An occasional deep scattering layer, most often observed during the daytime, had an almost flat frequency response. There is evidence in the literature that scattering from myctophids, small fish, some with and some without swimbladders, can give rise to a relatively flat, or even decreasing, backscattering spectrum between 38 and $200 \mathrm{kHz}$ (Kloser et al., 2002; Mair et al., 2005). Myctophids, and fish more generally, are known to effectively avoid net systems such as the $1-\mathrm{m}^{2}$ MOCNESS, and very few individuals were captured in the nets. Thus it was not possible to quantitatively account for the scattering from fish in this study. However, the measured scattering observed throughout most of this study was generally consistent with scattering from zooplankton, that is, the scattering generally increased with increasing frequency across the frequency range of interest.
The scattering levels predicted by use of the models and net tow information were approximately $10 \mathrm{~dB}$ lower than the observed scattering at most frequencies and depths if the siphonophore pneumatophores were not included. Inclusion of the pneumatophores reduced, but did not completely remove, the discrepancies between the predicted and observed scattering levels. Inclusion of the pneumatophores resulted in a general tendency to over predict the observed scattering at $43 \mathrm{kHz}$, and most likely is a result of uncertainty in the hybrid scattering model and the high sensitivity of the resonance frequencies to small errors in the measured pneumatophore size, as most resonance frequencies occurred below $120 \mathrm{kHz}$. Net avoidance and the destruction of fragile organisms are likely to be significant contributors to the general tendency of under predicting the observed scattering.

Though the correlation between observed and predicted scattering was not as good as some other studies (Flagg and Smith, 1989; Wiebe et al., 1997; Ressler, 2002; Fielding et al., 2004), the key difference is that this study includes data from multiple locations, collected at different times of the day and night, at different times of the year, at multiple frequencies, and in heterogeneous zooplankton populations in which one particular type of scatterer does not often dominate at all frequencies. It is also of interest to note that the daily vertical migration of zooplankton, in which some zooplankton taxa migrate but others do not, changes the relative day/night abundances of different zooplankton at any given depth, potentially affecting the balance of dominant scatterers. However, no systematic differences between the predictions based on the day and night tows were observed.

Measured volume backscattering was also compared to model predictions that used coincident video images. Though the predicted scattering based on the video images could not explain all of the vertical layering observed acoustically, there was relatively good agreement between the predictions and the acoustic observations at high frequencies at depths where copepods dominated the biomass. The video-imagebased estimates of abundance and depth distribution for copepods were in good agreement with the net tow observations, though the comparison was poor for all other zooplankton taxa. Based on the restricted analysis completed thus far it is concluded that the video imaging technique is suited to providing the ground-truthing information needed to compare predicted to observed scattering only in locations where rare scatterers do not dominate the scattering. More extensive quantitative analysis of the existing video images should allow larger regions of the acoustic data to be interpreted in terms of the abundance and size of copepods.

Two types of inversions of the volume backscattering data were performed: 1) At locations where the predicted scattering was dominated at all frequencies by gas-bearing siphonophores (Table IV), least-squares inversions of the multi-frequency data were performed to obtain both numerical abundance and size (Table V), as has been done previously in the literature (Warren et al., 2003; Trevorrow et al., 2005). Though this multi-frequency inversion produced accurate estimates of size, there were significant discrepancies between the acoustically inferred and directly measured net tow abundance. This difference, involving relatively large 
and more mobile zooplankton, is believed to be largely due to net avoidance (Wiebe et al., 2004 and references therein) and destruction of these fragile zooplankton, although there is also error associated with the scattering model and input parameters. 2) At locations where the predicted scattering was dominated at a single frequency by a single zooplankton taxon, namely copepods or pteropods (Table IV), simple single-frequency calculations of abundance, assuming a single known size, were performed (Table V). The acoustically inferred abundances compared quite favorably to net or video samples.

The discrepancy between the acoustically inferred and directly measured net abundance found in this study has not been observed in some other multi-frequency studies involving acoustic sampling volumes many orders of magnitude smaller than the sampling volume employed in the current study (e.g., $0.01 \mathrm{~m}^{3}$ in Pieper et al. (1990) versus $21-86 \mathrm{~m}^{3}$ in the current study) and in which large and less abundant zooplankton are less likely to be sampled. As a consequence the primary contributors to the measured scattering are often small and abundant zooplankton, such as copepods, resulting in more accurate estimates of abundance (e.g. Costello et al., 1989; Pieper et al., 1990; Napp et al., 1993). However, larger sampling volumes are better suited to synoptic surveys of large regions and will contain many different taxa that potentially span multiple trophic levels. Under certain restricted conditions, abundance estimates of the smaller, more abundant, and less mobile zooplankton using the large sampling volume synoptic system were also in relatively good agreement (Table V).

In conclusion, one of the main goals of high-frequency acoustic scattering techniques that make use of instruments like the BIOMAPER-II, is to rapidly sample broad areas acoustically for the purpose of making inferences of biological quantities, such as the abundance of zooplankton. It is well known that multi-frequency acoustic scattering techniques can increase the amount of information regarding the distribution of heterogeneous zooplankton populations over relevant spatial and temporal scales, relative to more traditional sampling methods alone. However, in order to infer biological parameters from the acoustic data it is necessary to first determine the dominant scatterers (Table IV), for which direct ground-truthing measurements and accurate scattering models are currently essential. The larger the number of frequencies over which a single type of scatterer dominates, the more biological parameters that can be inferred (Table V). When one type of scatterer only dominates at a single frequency, the mean size of the dominant scatterer obtained by the ground-truthing measurements can be used to acoustically infer the abundance. However, small errors in the measured size, in addition to a broad distribution of sizes of the dominant scatterer, can lead to large errors in the acoustically inferred abundance, particularly when the dominant scatterer is a gas-bearing organism with a relatively strong and narrow resonance frequency, and the frequencies available are close to the resonance frequency (as was the case in this study).

A major contribution of this study has been to show that in mixed zooplankton populations, one type of scatterer does not often dominate the scattering at all frequencies. In fact, at many locations, no single type of scatterer dominates at any frequency.

Looking to the future, acoustic systems that take advantage of emerging broadband technology will be better placed to address this problem. For example, a broadband system continuously spanning $30-150 \mathrm{kHz}$ might have allowed the pneumatophore resonance frequencies (hence size) to be determined. However, due to the complexities associated with interpreting scattering from mixed zooplankton populations as outlined in this study, even with unlimited bandwidth, well-parameterized and accurate scattering models, and robust in situ information, accurate interpretation of volume scattering data will most likely remain restricted to limited conditions.

\section{ACKNOWLEDGMENTS}

The authors would like to thank Dezhang Chu for generously providing the computer code for calculating volume backscattering from some zooplankton. The authors would also like to thank Joe Warren for his assistance and participation during the GoM field surveys, and for providing length-to-width measurements of euphausiids specific to the GoM. Finally, comments from two anonymous reviewers led to significant improvement of this manuscript. This research was supported in part by the U.S. GLOBEC program, NOAA (Grant nos. NA17RJ1223 and NA67RJ0148), the James S. Cole and Cecily C. Selby Endowed Funds, the Penzance Endowed Fund for Support of Assistant Scientists, and the Adams Chair at the Woods Hole Oceanographic Institution. A selected number of focused experiments were also funded by the ONR (Grant No. N00014-98-1-0362). This is GLOBEC contribution number 541.

Anderson, V. C. (1950). "Sound scattering from a fluid sphere," J. Acoust. Soc. Am. 22, 426-431.

Benfield, M. C., Davis, C. S., Wiebe, P. H., Gallager, S. M., Lough, R. G., and Copley, N. J. (1996). "Video plankton recorder estimates of copepod, pteropod and larvacean distributions from a stratified region of Georges Bank with comparative measurements from a MOCNESS sampler," DeepSea Res., Part II 43(7-8), 1925-1945.

Benfield, M. C., Wiebe, P. H., Stanton, T. K., Davis, C. S., Gallager, S. M., and Greene, C. H. (1998). "Estimating the spatial distribution of zooplankton biomass by combining Video Plankton Recorder and single-frequency acoustic data," Deep-Sea Res., Part II 45(7), 1175-1199.

Benfield, M. C., Davis, C. S., and Gallager, S. M. (2000). "Estimating the in situ orientation of Calanus finmarchicus on Georges Bank using the Video Plankton Recorder," Plankton Biol. Ecol. 47(1), 69-72.

Benfield, M. C., Lavery, A. C., Wiebe, P. H., Greene, C. H., Stanton, T. K., and Copley, N. J. (2003). "Distribution of physonect siphonulae in the Gulf of Maine and their potential as important sources of acoustic scattering," Can. J. Fish. Aquat. Sci. 60, 759-772.

Brierley, A. S., Ward, P., Watkins, J. L., and Goss, C. (1998). "Acoustic discrimination of southern ocean zooplankton,” Deep-Sea Res., Part II 45, $1155-1173$

Brierley, A. S., Alexsen, B. E., Boyer, D. C., Lyman, C. P., Didcock, C. A., Boyer, H. J., Sparks, C. A. J., Purcell, J. E., and Gibbons, M. J. (2004). "Single target detections of jellyfish," ICES J. Mar. Sci. 61, 383-393.

Brooks, D. A. (1996). "Physical oceanography of the shelf and slope seas from Cape Hateras to Georges Bank: A brief overview," The Northeast Shelf Ecosystem: Assessment, Sustainability, and Management, edited by K. Sherman, N. A. Jaworski, and T. J. Smayda (Blackwell Science, Cambridge, MA), Chap. 4.

Burgett, R. L., Hebert, D., and Oakey, N. S. (2001). "Vertical structure of turbulence on the southern flank of Georges Bank," J. Geophys. Res. 
106(C10), 22545-22558.

Chu, D., Foote, K. G., and Stanton, T. K. (1993). "Further analysis of target strength measurements of Antarctic krill at 38 and $120 \mathrm{kHz}$ : Comparison with deformed cylinder model and inference of orientation distribution," J. Acoust. Soc. Am. 93, 2985-2988.

Chu, D., and Stanton, T. K. (1998). "Application of pulse compression techniques to broadband acoustic scattering by live individual zooplankton," J. Acoust. Soc. Am. 104(1), 39-55.

Chu, D., Wiebe, P. H., and Copley, N. J. (2000). "Inference of material properties of zooplankton from acoustic and resistivity measurements," ICES J. Mar. Sci. 57, 1128-1142.

Chu, D., Wiebe, P. H., Copley, N. J., Lawson, G. L., and Puvanendran, V. (2003). "Material properties of North Atlantic cod eggs and early-stage larvae and their influence on acoustic scattering," ICES J. Mar. Sci. 60(3), 508-515.

Chu, D., and Wiebe, P. H. (2005). "Measurement of sound-speed and density contrasts of zooplankton in Antarctic waters," ICES J. Mar. Sci. 62, 818-831.

Costello, J. H., Pieper, R. E., and Holliday, D. V. (1989). "Comparison of acoustic and pump sampling techniques for the analysis of zooplankton distributions," J. Plankton Res. 4(11), 703-709.

David, P., Guerin-Ancey, O., Oudot, G., and Van Cuyck, J. P. (2001) "Acoustic backscattering from salp and target strength estimation," Oceanol. Acta 24(5), 443-451.

Davis, C. S., and Wiebe, P. H. (1985). "Macrozooplankton biomass in a warm-core Gulf Stream ring: Time series changes in size structure, taxonomic composition, and vertical distribution," J. Geophys. Res. 90, 88718882 .

Davis, D. S., Gallager, S. M., Berman, M. S., Haury, L. R., and Strickler, J. R. (1992). "The video plankton recorder (VPR): Design and initial results," Adv. Limnol. 36, 67-81.

Diachok, O. (2001). "Interpretation of the spectra of energy scattered by dispersed anchovies," J. Acoust. Soc. Am. 110(6), 2917-2923.

Endo, Y. (1993). "Orientation of Antarctic krill in an aquarium," Nippon Suisan Gakkaishi 59, 465-468.

Fielding, S., Griffiths, G., and Roe, H. S. J. (2004). "The biological validation of ADCP acoustic backscatter through direct comparison with net samples and model predictions based on acoustic-scattering models," ICES J. Mar. Sci. 60(2), 184-200.

Flagg, C. M., and Smith, S. L. (1989). "On the use of the Acoustic Doppler Current profiler to measure zooplankton abundance," Deep-Sea Res., 36, 455-474.

Foote, K. G., Knudsen, H. P., Vestnes, G., MacLennan, D. N., and Simmonds, E. J. (1987). "Calibration of acoustic instruments for fish-density estimation: A practical guide," ICES Cooperative Research Report No. 144.

Foote, K. G. (1990). "Speed of sound in Euphausia superba," J. Acoust. Soc. Am. 87, 1405-1408.

Gallager, S. M., Davis, C. S., Epstein, A. W., Solow, A., and Beardsley, R. C. (1996). "High-resolution observations of plankton spatial distribution correlated with hydrography in the Great South Channel, Georges Bank," Deep-Sea Res., Part I,43(7-8), 1627-1663.

Gauthier, G., and Rose, G. A. (2002). "In situ target strength studies on Atlantic redfish (Sebastes spp.)," ICES J. Mar. Sci. 59, 805-815.

Goodman, L. (1990). "Acoustic scattering from ocean microstructure," J. Geophys. Res. 95, 11557-11573.

Goodman, R. R., and Stern, R. (1962). "Reflection and transmission of sound by elastic spherical shells," J. Acoust. Soc. Am. 34(3), 338-344.

Gregg, M. (1987). "Diapycnal mixing in the thermocline: A review," J. Geophys. Res. 92, 5249-5286.

Haury, L. R., McGowan, J. A., and Wiebe, P. H. (1978). "Patterns and processes in the time-space scales of plankton distribution," in Spatial Pattern in Plankton Communities, edited by J. H. Steele (Plenum, New York), pp. 277-327.

Holliday, D. V., and Pieper, R. E. (1980). "Volume scattering strengths and zooplankton distributions at acoustic frequencies between 0.5 and 3 MHz," J. Acoust. Soc. Am. 67(1), 135-146.

Holliday, D. V., and Pieper, R. E. (1995). "Bioacoustical oceanography at high frequencies," ICES J. Mar. Sci. 52, 279-296.

Iida, K., Takahashi, R., Tang, Y., Mikua, T., and Sato, M. (2006). “Observations of marine animals using an underwater acoustic camera," Jpn. J. Appl. Phys., Part 1 45, 4875-4881.

Kils, U. (1981). "Swimming behavior, swimming performance and energy balance of Antarctic krill Euphausia superba," BIOMASS Sci. Series 3,
$1-22$.

Kloser, R. J. (1996). "Improved precision of acoustic surveys of benthopelagic fish by means of a deep-towed transducer," ICES J. Mar. Sci. 54, 407-413.

Kloser, R. J., Ryan, T., Sakov, P., and Koslow, J. A. (2002). "Species identification in deep water using multiple acoustic frequencies," Can. J. Fish. Aquat. Sci. 59, 1065-1077.

Korneliussen, R. J. (2000). "Measurement and removal of echo integration noise," ICES J. Mar. Sci. 57, 1204-1217.

Korneliussen, R. J., and Ona E. (2002). "An operational system for processing and visualizing multi-frequency acoustic data,” ICES J. Mar. Sci. 59, 293-313.

Lalli, C. M., and Gilmer, R. W. (1989). Pelagic Snails: The Biology of Holoplanktonic Gastropod Mollusks (Stanford University Press, Stanford, CA).

Lascara, C. M., Hofmann, E. E., Ross, R. M., and Quetin, L. B. (1999). "Seasonal variability in the distribution of Antarctic krill, Euphausia superba, west of the Antarctic Peninsula," Deep-Sea Res., Part I 46, 951984.

Lavery, A. C., Stanton, T. K., McGehee, D., and Chu, D. (2001). "Threedimensional modeling of acoustic backscattering from fluid-like zooplankton," J. Acoust. Soc. Am. 111(3), 1197-1210.

Lavery, A. C., Schmitt, R. W., and Stanton, T. K. (2003). "High-frequency acoustic scattering from turbulent oceanic microstructure: The importance of density fluctuations," J. Acoust. Soc. Am. 114(5), 2685-2697.

Lawson, G. L., Wiebe, P. H., Ashjian, C. J., Gallager, S. M., Davis, C. S., and Warren, J. D. (2004). "Acoustically-inferred zooplankton distribution in relation to hydrography west of the antarctic peninsula," Deep-Sea Res., Part II 51, 2041-2072.

Lawson, G. L., Wiebe, P. H., Ashjian, C. J., Chu, D., and Stanton, T. K. (2006). "Improved parameterization of Antarctic krill target strength models," J. Acoust. Soc. Am. 119(1), 232-242.

Mair, A. M., Fernandes, P. G., Lebourges-Dhaussy, A., and Brierley, A. S. (2005). "An investigation into the zooplankton composition of a prominent $38 \mathrm{kHz}$ scattering layer in the North Sea," J. Plankton Res. 27(7), 623-633.

McGehee, D. E., O’Driscoll, R. L., and Traykovski, L. V. M. (1998). "Effects of orientation on acoustic scattering from Antarctic krill at $120 \mathrm{kHz}$," Deep-Sea Res., Part II 45(7), 1273-1294.

Miyashita, K., Aoki, I., and Inagaki, T. (1996). "Swimming behaviours and target strength of isada krill (Euphausia pacifica)," ICES J. Mar. Sci. 53, 303-308.

Monger, B. C., Chinniah-Chandy, S., Meir, E., Billings, S., Greene, C. H., and Wiebe, P. H. (1998). "Sound scattering by the gelatinous zooplankters Aequorea victoria and Pleurobrachia bachei," Deep-Sea Res., Part II 45(7), 1255-1271.

Mutlu, E. (1996). "Target strength of the common jellyfish (Aurelia aurita): A preliminary experimental study with a dual-beam acoustic system," ICES J. Mar. Sci. 53(2), 309-311.

Napp, J. M., Ortner, P. B., Pieper, R. E., and Holliday, D. V. (1993). "Biovolume-size spectra of epipelagic zooplankton using a multifrequency Acoustic Profiling System (MAPS)," Deep-Sea Res., Part I 40(3), 445-459.

Oakey, N. S. (1982). "Determination of the rate of turbulent energy from simultaneous temperature and shear microstructure measurements," J. Phys. Oceanogr. 12, 256-271.

Ortner, P. B., Cummings, S. R., Aftring, R. P., and Edgerton, H. E. (1979). "Silhouette photography of oceanic zooplankton," Nature (London) 277, 50-51.

Pershing, A. J., Wiebe, P. H., Manning, J. P., and Copley, N. J. (2001). "Evidence for vertical circulation cells in the well-mixed area of Georges Bank and their biological implication," Deep-Sea Res., Part II 48(1-3), 283-310.

Pieper, R. E., Holliday, D. V., and Kleppel, G. S. (1990). "Quantitative zooplankton distributions from multifrequency acoustics," J. Plankton Res. 12(2), 443-441.

Pieper, R. E., McGehee, D. E., Greenlaw, C. F., and Holliday, D. V. (2001). "Acoustically measured seasonal patterns of zooplankton in the Arabian sea,” Deep-Sea Res., Part II 48(6-7), 1325-1343.

Ressler, P. (2002). "Acoustic backscatter measurements with a $153 \mathrm{kHz}$ ADCP in the northeastern Gulf of Mexico: Determination of dominant zooplankton and micronekton scatterers," Deep-Sea Res., Part I 49, 20352051.

Ross, T., and Lueck, R. (2003). "Sound scattering from oceanic turbulence," 
Geophys. Res. Lett. 30(6), 1344.

Ross, T., Garrett, C., and Lueck, R. (2004). "On the turbulent co-spectrum of two scalars and its effect on the acoustic scattering from oceanic turbulence," J. Fluid Mech. 514, 107-119.

Rothschild, B. J., and Osborn, T. R. (1988). "Small-scale turbulence and plankton contact rates," J. Plankton Res. 10, 465-474.

Seim, H. E., Gregg, M. C., and Miyamoto, R. T. (1995). "Acoustic backscatter from turbulent microstructure," J. Atmos. Ocean. Technol. 12(2), 367-380.

Seim, H. E. (1999). "Acoustic backscatter from salinity microstructure," J. Atmos. Ocean. Technol. 16(11), 1491-1498.

Seuront, L., Schmitt, F., and Lagadeuc, Y. (2001). "Turbulence intermittency, small-scale phytoplankton patchiness and encounter rates in plankton: Where do we go from here?" Deep-Sea Res., Part I 48(5), 1199-1215.

Stanton, T. K. (1989). "Simple approximate formulas for backscattering of sound by spherical and elongated objects," J. Acoust. Soc. Am. 86(4), $1499-1510$.

Stanton, T. K., Chu, D., Wiebe, P. H., and Clay, C. S. (1993). "Average echoes from randomly oriented random-length finite cylinders: Zooplankton models," J. Acoust. Soc. Am. 94, 3463-3472.

Stanton, T. K., Wiebe, P. H., Chu, D., Benfield, M. C., Scanlon, L., Martin, L., and Eastwood, R. L. (1994). "On acoustic estimates of zooplankton biomass," ICES J. Mar. Sci. 51, 505-512.

Stanton, T. K., Chu, D., Wiebe, P. H., Martin, L. V., and Eastwood, R. L. (1998a). "Sound scattering by several zooplankton groups. I. Experimental determination of dominant scattering mechanisms," J. Acoust. Soc. Am. 103(1), 225-235.

Stanton, T. K., Chu, D., and Wiebe, P. H. (1998b). "Sound scattering by several zooplankton groups. II. Scattering models," J. Acoust. Soc. Am. 103(1), 236-253.

Stanton, T. K., and Chu, D. (2000). "Review and recommendations for the modeling of acoustic scattering by fluid-like elongated zooplankton: Euphausiids and copepods," ICES J. Mar. Sci. 57, 793-807.

Stanton, T. K., Chu, D., Wiebe, P. H., Eastwood, R. L., and Warren, J. D. (2000). "Acoustic scattering by benthic and planktonic shelled animals," J. Acoust. Soc. Am. 108(2), 535-550.

Thorpe, S. A. (1977). "Turbulence and mixing in a Scottish loch," Philos. Trans. R. Soc. London, Ser. A 286, 125-181.

Thorpe, S. A., and Brubaker, J. M. (1983). "Observations of sound reflection by temperature microstrucure," Limnol. Oceanogr. 28, 601-613.

Trevorrow, M. V., and Tanaka, Y. (1997). "Acoustic and in situ measure- ments of freshwater amphipods (Jesogammarus annandalei) in Lake Biwa, Japan," Limnol. Oceanogr. 42(1), 121-132.

Trevorrow, M. V., Mackas, D. L., and Benfield, M. C. (2005). "Comparison of multifrequency acoustic and in situ measurements of zooplankton abundance in Knight Inlet, British Columbia," J. Acoust. Soc. Am. 117(6), 3574-3588.

Warren, J. D., Stanton, T. K., Benfield, M. C., Wiebe, P. H., Chu, D., and Sutor, M. (2001). "In situ measurements of acoustic target strength of gas-bearing siphonophores," ICES J. Mar. Sci. 58, 740-749.

Warren, J. D. (2001). "Estimating Gulf of Maine zooplankton distributions using multiple frequency acoustics, video, and environmental data," $\mathrm{Ph} . \mathrm{D}$. thesis, MIT/WHOI, Cambridge, MA, 2001-2003.

Warren, J. D., Stanton, T. K., Wiebe, P. H., and Seim, H. E. (2003). "Inference of biological and physical parameters in an internal wave using multiple-frequency, acoustic-scattering data," ICES J. Mar. Sci. 60(5), 1033-1046

Weston, D. E. (1967). "Sound propagation in the presence of bladder fish," in Underwater Acoustics, edited by V. Albers (Plenum, New York), Vol. 2, Chap. 5, pp. 55-88.

Wiebe, P. H., Morton, A. W., Bradley, A. M., Backus, R. H., Craddock, J. E., Barber, V., Cowles, T. J., and Flierl, G. R. (1985). "New developments in the MOCNESS, an apparatus for sampling zooplankton and micronekton," Mar. Biol. (Berlin) 87(3), 313-323.

Wiebe, P. H., Mountain, D. G., Stanton, T. K., Greene, C. H., Lough, G., Kaartvedt, S., Dawson, J., and Copley, N. (1996). "Acoustical study of the spatial distribution of plankton on Georges Bank and the relationship between volume backscattering strength and the taxonomic composition of the plankton," Deep-Sea Res., Part II 43(7-8), 1971-2001.

Wiebe, P. H., Stanton, T. K., Benfield, M. C., Mountain, D. G., and Greene, C. H. (1997). "High-frequency acoustic volume backscattering in the Georges Bank coastal region and its interpretation using scattering models," IEEE J. Ocean. Eng. 22(3), 445-464.

Wiebe, P. H., Stanton, T. K., Greene, C. H., Benfield, M. C., Sosik, H. M., Austin, T., Warren, J. A., and Hammar, T. (2002). "BIOMAPER II: An integrated instrument platform for coupled biological and physical measurements in coastal and oceanic regimes," IEEE J. Ocean. Eng. 27, 700716

Wiebe, P. H., Ashjian, C. J., Gallager, S. M., Davis, C. S., Lawson, G. L., and Copley, N. J. (2004). "Using a high-power strobe light to increase the catch of Antarctic krill,” Mar. Biol. (Berlin) 144, 493-502. 